\title{
Evolution of Insulin Development: Focus on Key Parameters
}

\author{
Joseph M. Tibaldi
}

To view enhanced content go to www.advancesintherapy.com Received: April 26, 2012 / Published online: July 27, 2012

(C) The Author(s) 2012. This article is published with open access at Springerlink.com

\section{ABSTRACT}

Introduction: Although insulin products and treatment strategies have improved significantly, clinical challenges still exist. Meeting glycemic goals while minimizing glucose variability and hypoglycemia is of utmost importance when considering existing insulin therapies and designing investigational insulin treatments.

Methods: A PubMed search identified relevant, peer-reviewed articles related to the evolution of insulin development for this nonsystematic review. Search terms included "animal insulin," "synthetic insulin," "regular human insulin," "insulin lispro," "insulin aspart," "insulin glulisine," "insulin glargine," "insulin detemir," "insulin degludec," "biphasic human insulin,"

J. M. Tibaldi $(\triangle)$

Diabetes and Endocrine Associates, 59-45 161 Street, Flushing, NY 11365, USA

e-mail: jtibaldi@aol.com

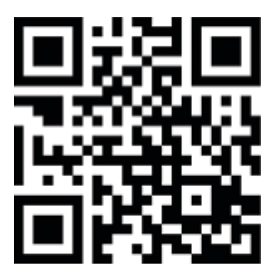

Enhanced content for Advances in Therapy articles is available on the journal web site: www.advancesintherapy.com "insulin premixes," "ultra-long acting," "oral insulin," and "inhaled insulin."

Results: While the discovery of animal insulin significantly decreased mortality rates from diabetes, issues with availability and large variability between batches led to difficulty in determining proper doses and, subsequently, challenges in achieving glycemic control and avoiding hypoglycemia. The development of synthetic insulin created a more readily available supply, but hypoglycemia still persisted. Recombinant DNA technology solved insulin production problems and allowed for the development of better retarding agents, but pharmacokinetic/pharmacodynamic profiles still did not mimic natural insulin. Insulin premixes offered improved glycemic control, decreased intrapatient variability versus selfmixing, and required fewer injections per day; however, patient adherence remained a problem due to the need to inject 30-60 minutes before a meal for optimal control. This prompted the development of rapid-acting insulin analogs that could be injected right before a meal and long-acting insulin analogs with flatter timeaction profiles.

Conclusion: Despite advances in insulin development, a need to provide more 
physiologic basal insulin coverage and reduce hypoglycemic risk in patients with diabetes remains. Newer insulin analogs and more convenient routes of insulin delivery have shown promising safety and efficacy results. Many patients with diabetes have not reached glycemic goals on currently available insulins. Additional studies are necessary to tailor optimal insulin delivery strategies to specific subsets of diabetes patients.

Keywords: Animal insulin; Diabetes; Hypoglycemia; Insulin; Insulin analogs; Regular human insulin; Synthetic insulin

\section{INTRODUCTION}

Since the breakthrough discovery of insulin in 1921, insulin preparation methods and treatment strategies have advanced significantly. However, clinical challenges regarding the management of diabetes with insulin still exist. Meeting glycemic goals while minimizing glucose variability and hypoglycemia is of utmost importance when considering existing insulin therapies and designing investigational insulin treatments. Insulin products must also meet patient lifestyle requirements to help increase adherence. For example, it would be ideal for all patients on basal insulin to inject only once a day.

Although initial preparations of insulin from animal sources were successful in treating patients with diabetes, these early insulins had highly variable efficacy. Impurities in animal insulin products were associated with side effects such as insulin allergy and lipoatrophy, prompting researchers to develop methods for insulin purification [1]. Therefore, synthetic and recombinant "human" insulins were developed to enhance insulin purity as well as reproducibility of response. The production of these insulins, along with advances in animal insulin purification, significantly decreased insulin allergy and lipoatrophy. However, these preparations did not fully mimic endogenous insulin secretion, and hypoglycemia remained a common adverse effect [2].

Long-acting (basal) insulin analogs were developed to provide a more physiologic pharmacokinetic/pharmacodynamic (PK/PD) profile with longer duration, less intrapatient variability, less pronounced peak in time-action profiles, and decreased hypoglycemic risk compared with human insulins [3]. Although long-acting insulin analogs have improved PK/PD profiles and have reduced the safety concerns in patients with both type 1 and type 2 diabetes, up to $40 \%$ of patients still require twicedaily injections of long-acting insulin analogs, as the currently available basal insulins do not last 24 hours in some patients [3-5]. These patients in particular could benefit from insulin options with longer time-action profiles. In addition to long-acting insulin analogs, rapid-acting (bolus) insulin analogs were developed to fulfill a need for insulin with a faster onset and shorter duration than regular human insulin (RHI) [6]. Together with long-acting insulin analogs, rapid-acting insulin analogs better simulate endogenous insulin secretion.

Further enhancements are still necessary to ensure optimal insulin treatment. A major goal of investigational insulins, including ultralong-acting, inhaled, and oral insulins, is to provide optimal insulin coverage that more closely mimics endogenous insulin secretion, while decreasing the risk of hypoglycemia and improving adherence. This will ultimately improve glycemic control and minimize complications. Inhaled and oral insulins also represent potential noninvasive routes of insulin administration, which could improve patient adherence [7-9]. This review will discuss the 
evolution of insulin development from early animal insulin to current investigational insulin, with a focus on limitations and how they were, or will be, overcome.

Because diabetes is a chronic condition, attention to patient lifestyle considerations is important in insulin development to better empower patients and improve adherence. Indeed, more physiologic PK/PD parameters can facilitate adherence by allowing dosing times that better fit the daily schedules of patients. Subcutaneous insulin administration presents a challenge for patients who fear the pain or inconvenience of injection [10], something that has been and continues to be addressed by ongoing improvements in insulin pen devices and needles.

As insulin has evolved, so has the definition of a unit of insulin. The definition of one unit of insulin is, "the amount of insulin that will lower the blood glucose of a healthy $2 \mathrm{~kg}(4.4 \mathrm{lb})$ rabbit that has fasted for 24 hours to $2.5 \mathrm{mmol} / \mathrm{L}$ (45 mg/dL) within 5 hours" [11].

\section{LITERATURE SEARCH METHODOLOGY}

Information for this narrative, nonsystematic review was gathered by reviewing clinical trial data. A PubMed literature search was conducted to identify relevant, peer-reviewed clinical and review articles published between 1980 and September 2011 related to the evolution of insulin development. Search terms included "animal insulin," "synthetic insulin," "regular human insulin," "insulin lispro," "insulin aspart," "insulin glulisine," "insulin glargine," "insulin detemir," "insulin degludec," "biphasic human insulin," "insulin premixes," "ultra-long acting insulin," "oral insulin," and "inhaled insulin." Case studies and editorials were excluded. Primary manuscripts and reviews were included and an assessment of the study design, methodology, clinical relevance, and impact on the evolution of insulin development was performed. In addition, the bibliographies of articles of interest were reviewed and key references were obtained. A total of 92 articles was selected and analyzed.

\section{ANIMAL INSULIN}

\section{Reduction of Mortality, Adverse Events, and Emergence of Hypoglycemia}

Before the discovery of insulin, type 1 diabetes was a fatal disease due to the inevitable development of diabetic ketoacidosis in the late stages of the disease process [12]. At that time, the goal of treatment was limited to reducing mortality, with no caveats to reach that goal. Insulin treatment vastly increased the life expectancy of patients with diabetes and allowed them to meet treatment goals. However, glass syringes were used and the needles required sharpening before injection. This early insulin came from the purification of porcine or bovine pancreases [13], and within a few years after its discovery, the limitations of animal insulin became increasingly apparent. Common adverse effects in early insulin treatment included insulin allergy, abscesses, lipodystrophy, and insulin antibody formation. These adverse effects were mainly related to the impurity and species specificity of the insulin preparations $[1,13]$. As insulin purification techniques improved, the duration of action of insulin decreased, and patients required multiple injections throughout the day to avoid severe glycosuria [12]. This often led to either poor patient adherence or alternating extremes of hyperglycemia and hypoglycemia resulting from the boluses of these shorter-acting formulations [12]. As concerns regarding hypoglycemia emerged as 
an obstacle to effective treatment with insulin, encouraging patients to adhere to treatment regimens became a priority and the driving force behind further insulin development.

The first slow-release insulins using the animal protein protamine were developed in 1936. These insulins reduced, but did not eliminate, the incidence of hypoglycemic episodes [14]. The first slow-release insulin, neutral protamine Hagedorn (NPH), was an intermediate-acting complex of protamine, a protein isolated from fish sperm that reduced the solubility of insulin and zinc [12]. NPH was originally made by combining protamine with animal insulin, but was later added to insulin that was produced using recombinant DNA technology. It is so named because NPH was developed in the Hagedorn Laboratory in Denmark by Nordisk in 1946 [15]. Interestingly, NPH was considered a long-acting basal agent before the development of basal insulin analogs although its duration of action is only $12-18$ hours $[16,17]$. In addition, with NPH there is a shift in the peak with larger doses due to the depot effect, which, clinically, is a limiting factor [18]. A high level of hypoglycemia, particularly nocturnal hypoglycemia, was and still is one of the major limitations of NPH [19]. While gains were made in patient convenience, the issue of hypoglycemia remained.

In the 1970s, the production of highly purified animal insulins reduced the insulin dose needed for diabetes control and partially prevented local reactions such as lipoatrophy [20]. In one study, lipoatrophy was found in 49 of $511(9.6 \%)$ patients with diabetes treated with conventional therapy, but not in those treated solely with very pure porcine insulin [20]. However, in later studies, sporadic cases of lipoatrophy were reported with both highly purified porcine and bovine insulin, indicating that this side effect had not been completely eliminated [21]. Therefore, while the insulin purification process decreased the incidence of adverse events, further improvements were still necessary.

\section{Variable Efficacy and Risk of Hypoglycemia with Animal Insulin}

Large-scale production of insulin following its initial discovery was challenging, partly due to the temperature and $\mathrm{pH}$ variability between batches. A collaboration between Eli Lilly and the Toronto group of Banting, Best, Collip, Campbell, Fletcher, Macleod, and E.C. Noble led to the production of more potent porcine insulin preparations in mid-1922 [13]. However, the lot-to-lot potency still varied by $25 \%$, so physicians had to be constantly on the lookout for signs of hypoglycemia from excessive insulin [13]. Eli Lilly and Company's chief chemist George Walden developed the isoelectric precipitation method to improve the stability and purity of insulin significantly [13]. However, standardization problems persisted, with consistency from batch to batch still varying by $10 \%$ [13].

\section{Insulin Efficacy Criteria}

Measurements of insulin efficacy have evolved along with the development of new insulins. Before the introduction of hemoglobin A1c $\left(\mathrm{HbA}_{1 \mathrm{c}}\right)$ in 1976 as a means of monitoring longterm blood glucose levels [22], insulin efficacy was generally assessed using postprandial glucose (PPG) and fasting plasma glucose (FPG) levels. $\mathrm{HbA}_{1 \mathrm{c}}$, the measure of circulating glycated hemoglobin over the previous 2-3-month period, has since become the standard for evaluating the success of diabetes treatment regimens [23]. The relative contributions of PPG and FPG to 
$\mathrm{HbA}_{1 \mathrm{c}}$ in patients with type 2 diabetes can vary depending on the $\mathrm{HbA}_{1 \mathrm{c}}$ level. PPG and FPG should be considered individually when administering insulin therapy due to their potential for predicting other health risks. For example, PPG greater than $7.8 \mathrm{mmol} / \mathrm{L}$ in patients with normal FPG is associated with a two times greater risk of cardiovascular disease-related death [24]. However, the Longterm Study of Nateglinide + Valsartan to Prevent or Delay Type II Diabetes Mellitus and Cardiovascular Complications (NAVIGATOR) trial showed that targeting PPG did not reduce the risk of extended composite cardiovascular outcomes (death from a cardiovascular cause, nonfatal myocardial infarction, nonfatal stroke, hospitalization for heart failure, arterial revascularization, or hospitalization for unstable angina) [25]. Another study, Hyperglycemia and Its Effect After Acute Myocardial Infarction on Cardiovascular Outcomes in Patients With Type 2 Diabetes (HEART2D), did show a reduction in cardiovascular mortality risk in elderly (>65.7 years) acute myocardial infarction survivors when targeting PPG versus FPG [26]. Therefore, $\mathrm{HbA}_{1 \mathrm{c}}$, PPG, and FPG might all have clinical relevance as measurements of insulin efficacy.

\section{SYNTHETIC INSULINS}

Synthetic insulins were developed to provide patients with diabetes a potentially more effective and more readily available alternative to animal insulins. Following the characterization of the amino acid structure of human insulin, synthetic insulin was produced in American, German, and Chinese laboratories in the 1960s [27-29], making insulin the first protein ever synthesized in vitro [30]. Synthetic insulin with the amino acid structure of human insulin is prepared using several techniques, including total chemical synthesis, semisynthesis, which involves substituting the alanine in porcine insulin with threonine, and recombinant DNA methods [31, 32]. In the first clinical trial of insulin produced by total chemical synthesis (CGP 12831), six patients with diabetes showed evidence of full biologic action of the synthetic insulin [29]. Ketoacidosis was corrected in one patient, and synthetic insulin normalized the hyperglycemia in a patient with poor response to oral antidiabetic drugs [29]. However, two patients experienced more sudden hypoglycemic events than with animal insulin [29]. Another study investigating the safety and efficacy of semisynthetic human insulin in healthy patients found no difference in the potency, onset, and duration of effect between semisynthetic and porcine insulins [31]. Furthermore, in a study of patients with type 1 diabetes, semisynthetic insulin also showed no significant differences in blood glucose control and subcutaneous absorption compared with porcine insulin [32]. Together, these data suggested that synthetic insulins were a more viable option for most patients with diabetes than animal insulins. However, hypoglycemia remained a significant concern.

\section{REGULAR HUMAN INSULINS}

\section{Advances in Insulin Production but Still Problems with Glycemic Control}

The development of recombinant DNA technology finally allowed for the largescale synthesis of insulin. In 1978, scientists from Genentech used recombinant DNA technology to synthesize the A and B chains of insulin in Escherichia coli [33]. In vivo, insulin is synthesized from cleavage of a large polypeptide proinsulin that generates 
a $\mathrm{C}$ peptide and covalently links the $\mathrm{A}$ and B chains of insulin together (Fig. 1) [34, 35]. However, when insulin is made in vitro with
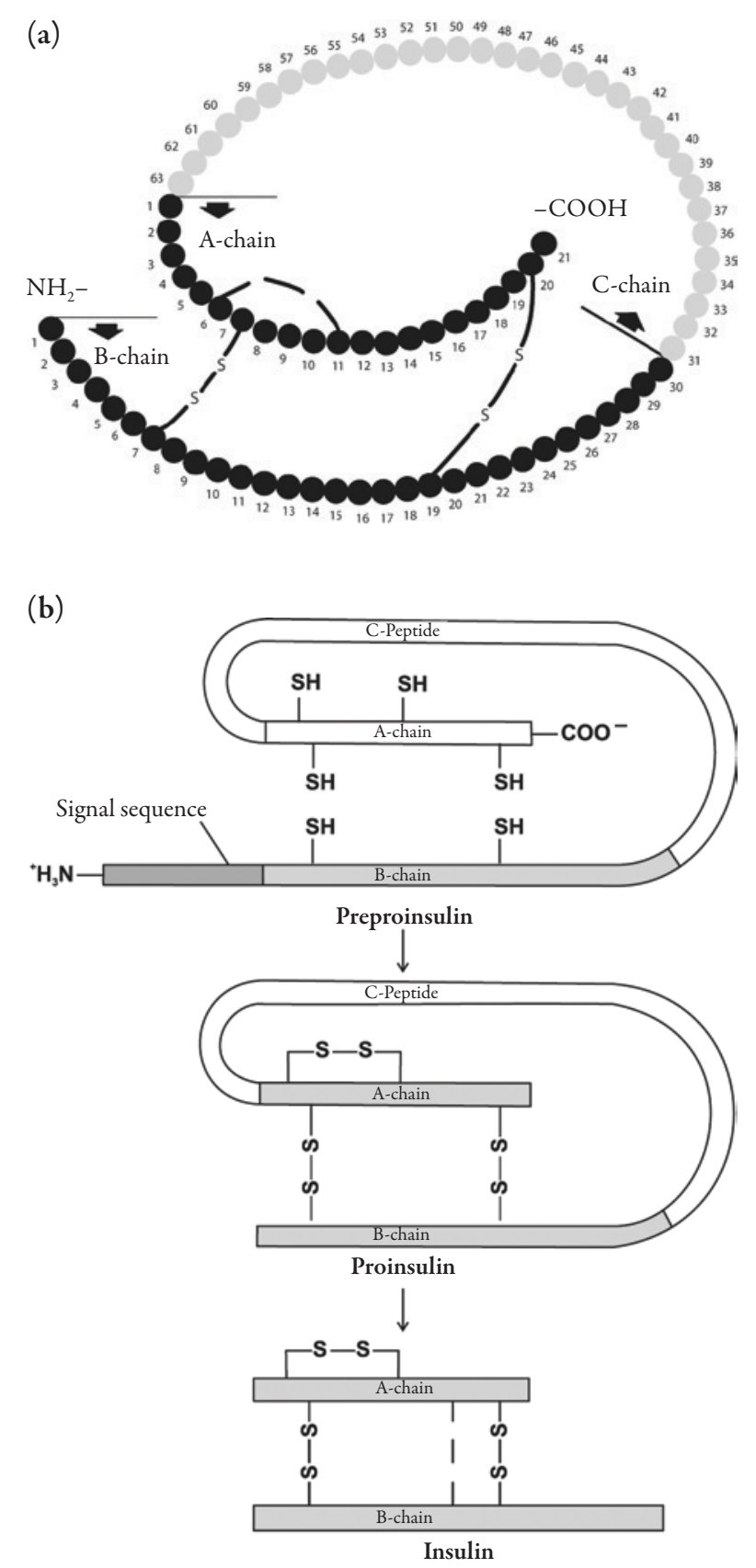

Fig. 1 Structure (a) and biosynthesis of insulin (b) [34]. Reprinted from the Journal of the Association of Physicians of India, Vol. 55, Joshi SR, Parikh RM, Das AK, "Insulin - history, biochemistry, physiology and pharmacology," pp. 20-21, 2007, with permission from Dr. Siddharth N. Shah for the Association of Physicians of India recombinant DNA technology, the A and B chains are synthesized separately using E. coli, and then joined together biochemically [33]. In 1982, Eli Lilly and Company [36] developed a short-acting insulin called Humulin R [37] and an intermediate-acting NPH insulin called Humulin N [38]. Human insulin synthesized by recombinant DNA technology was first tested in 17 healthy male volunteers [39], and it had similar glucose-lowering properties when compared to purified porcine insulin [39]. Therefore, RHI appeared to be a good alternative to animal insulin. Novo Nordisk also started producing biosynthetic human insulin (BHI) in 1987 [40].

Advances in insulin purity, species, and characteristics of the retarding agent were observed during the development of RHI [16]. However, the PK/PD properties of regular and intermediate-acting human insulin did not accurately match the insulin secretion pattern of a healthy patient without diabetes. In patients who do not have diabetes, insulin rises to a maximum concentration 30-45 minutes after ingestion of food, followed by a decline to basal levels after 2-3 hours [16]. The slow onset

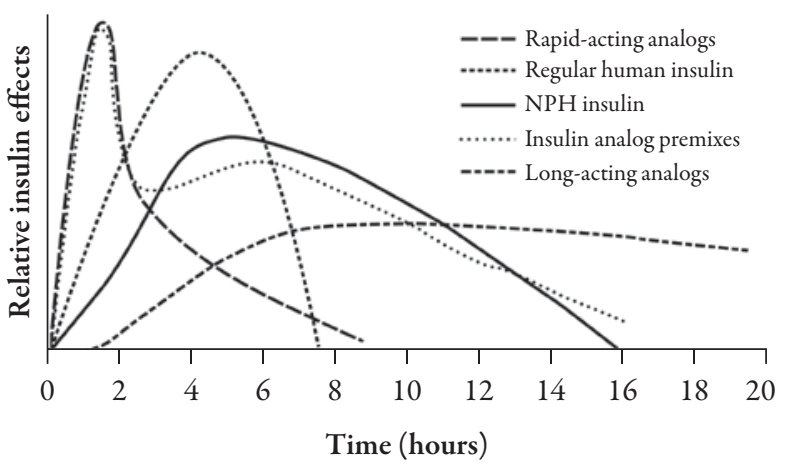

Fig. 2 Comparison of insulin time-action profiles [41]. Reprinted from Consultant, July 2009 Supplement, Brunton $S$, "Safety and effectiveness of modern insulin therapy: the value of insulin analogs," p. S15, 2009, with permission from UBM Medica 
and long duration of action of RHI (Fig. 2 [41]) increases a patient's risk of developing early postprandial hyperglycemia followed by hypoglycemia before the next meal [16]. The effect of the intermediate-acting NPH lasts only 12-18 hours (Fig. 2 [41]) [17], and there is considerable inter and intra-subject variation in bioavailability [16], because NPH is a suspension that must be mixed before injection $[16,17]$. Even in clinical research centers, the variability of the glucose infusion rate approaches $68 \%$ using clamp data. Differences in the site of injection can lead to variability in the absorption of NPH [16]. Furthermore, in a double-blind crossover trial, treatment with porcine or bovine insulin was compared with BHI in 94 patients with diabetes [42]. FPG levels were higher during BHI treatment than during treatment with animal insulin (14.2 vs. $12.8 \mathrm{mmol} / \mathrm{L}$ and 12.1 vs. $9.6 \mathrm{mmol} / \mathrm{L}$ in the bovine and porcine groups, respectively). This was presumably due to the different pharmacokinetic properties of BHI. Consistent with this, previous evidence showed that $\mathrm{BHI}$ is absorbed, and likely excreted or inactivated, more quickly than purified porcine insulin in normal subjects. Patients' willingness to adhere to therapy can be greatly undermined by the dosing inconvenience of RHI and NPH and the potential hypoglycemic episodes because of the extended duration of effect with larger doses of NPH $[18,43]$. As RHI has a relatively slow onset, it needs to be administered 30-60 minutes before a meal, the time of which can be difficult to predict. Therefore, short-acting analogs that can be injected right before a meal were needed $[16,44]$. Because of the limitations of both RHI and NPH and the need to mimic more closely the insulin secretion of a healthy patient, mixing NPH and RHI was common, but often resulted in crosscontamination and more inter and intrapatient variability, leading to the development of insulin premixes.

\section{Human Insulin Premixes: Improvement in Glycemic Control and Patient Lifestyle Concerns}

Insulin premixes, which contain a mixture of intermediate and short-acting insulins in the same vial, were developed to improve glycemic control over RHI or NPH alone. They also allow the patient to administer fewer daily injections than classic basal-bolus therapy, which requires injections of rapid-acting insulin before meals and intermediate or long-acting insulin in the morning or at bedtime. Biphasic human insulin 30 (BHI 30) consists of 30\% shortacting human insulin and $70 \% \mathrm{NPH}$, and has a duration of action up to 24 hours in some patients and a maximum effect between 2 and 8 hours $[45,46]$. Through further innovation, these premixes are now available in pen devices, eliminating the need for separate vials and syringes. Administering treatment with pen devices has ultimately decreased patient dosing errors and intrapatient variability associated with calculating the dosage of each component and mixing [47]. However, the same limitations of RHI and NPH persist.

\section{INSULIN ANALOGS}

\section{Development of Insulin Analogs}

By the early 1990s, great strides had been made in the development of insulin. Although animal insulin decreased mortality rates from diabetes, availability issues and large variability between batches led to difficulty in determining proper doses and hypoglycemia. While the availability of synthetic insulin reduced some of these concerns, hypoglycemia remained a major issue and patients required multiple injections throughout the day. Furthermore, while recombinant DNA technology resolved 
insulin production problems and allowed for the development of better retarding agents, the $\mathrm{PK} / \mathrm{PD}$ profile of synthetic insulin still did not mimic endogenous insulin. Insulin premixes improved glycemic control, decreased intrapatient variability due to mixing, and required fewer injections per day, which was easier for patients to manage. However, patient adherence to insulin regimens was still problematic due to the need to inject 30-60 minutes before a meal, reluctance to use syringes, intrapatient variability with preparation of vials and syringes, and the inconvenience of multiple injections per day. Despite the development of pen devices, vials and syringes were still the most common method of administration. Therefore, new insulin preparations were needed that provided either a faster onset and shorter duration of action and could be administered right before meals or a longer-acting, flatter time-action profile to sustain patients between injections [16].

Insulin analogs were designed to provide either a basal or bolus option to stimulate normal insulin physiology and secretion more closely,

(a)

A-chain

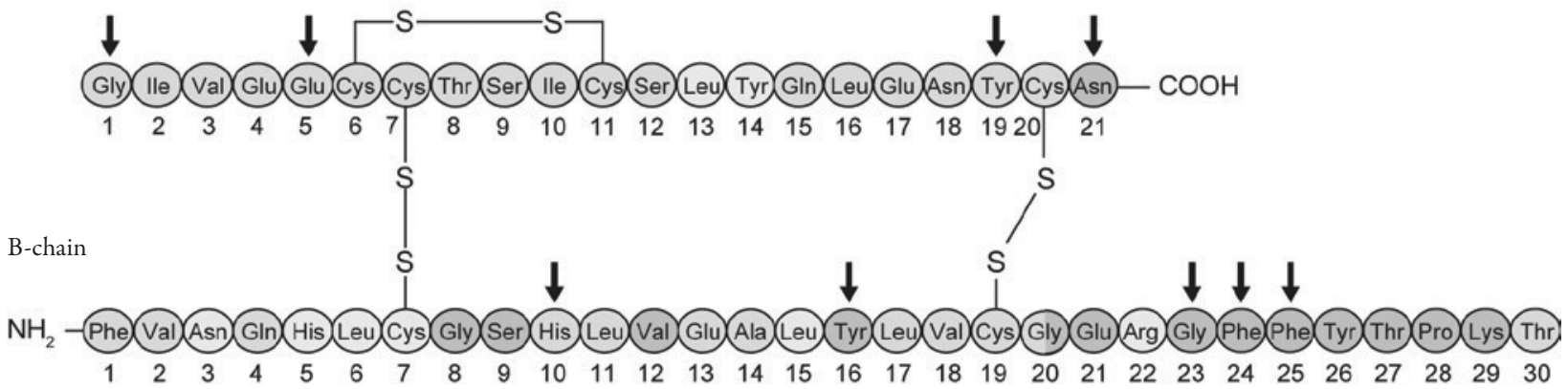

(b)

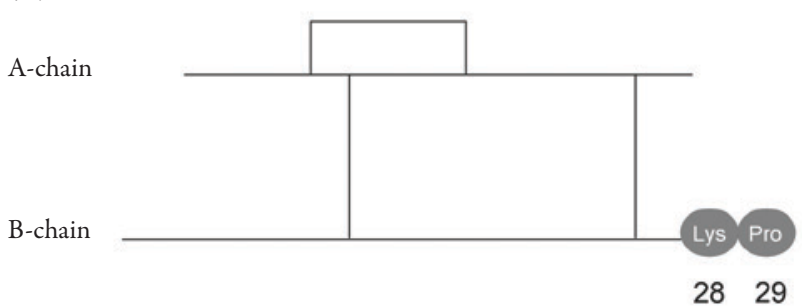

(c)

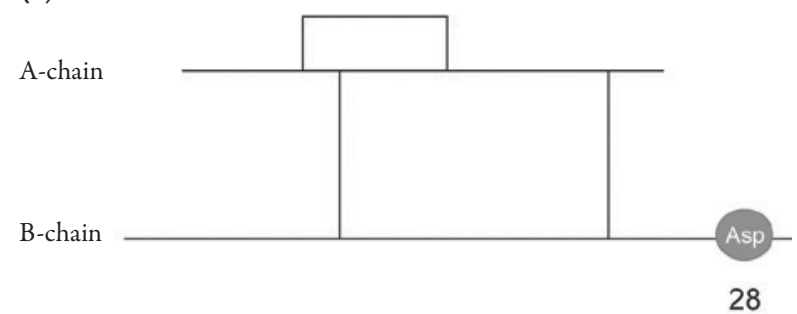

(d)

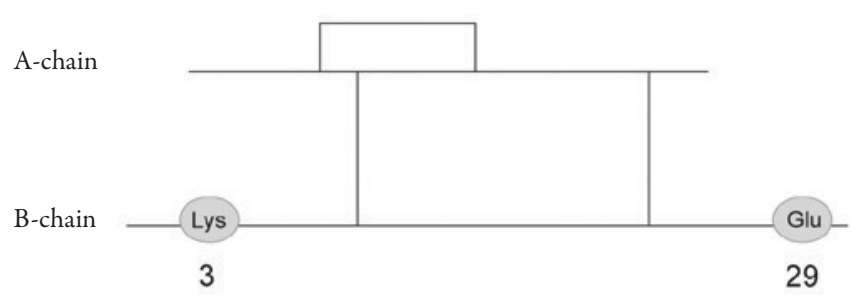

Fig. 3 Molecular structure of human insulin and rapid-acting insulin types - (a) human insulin, (b) insulin lispro, (c) insulin aspart, and (d) insulin glulisine [49]. NPH neutral protamine Hagedorn. Reprinted from Diabetes, Metabolic Syndrome and Obesity: Targets and Therapy, Vol. 2, Yamada S, "Insulin glulisine in the management of diabetes," p. 112, 2009, with permission from Dove Medical Press Ltd 
reduce hypoglycemia, and allow for improved absorption [2, 48]. Insulin consists of a 21 amino acid-long A chain and a 30 amino acid-long B chain (Fig. 3a) [49]. The substitution of amino acids at specific locations along either of these chains forms the basis of insulin analog production.
Substitutions at the $\mathrm{N}$ terminus of the A chain and the $\mathrm{C}$ terminus of the $\mathrm{B}$ chain can change the avidity of insulin to its receptor, as these regions are the sites of receptor binding. In addition, the $\mathrm{C}$ terminal of the $\mathrm{B}$ chain is critical for the conversion of stable insulin hexamers

(a)

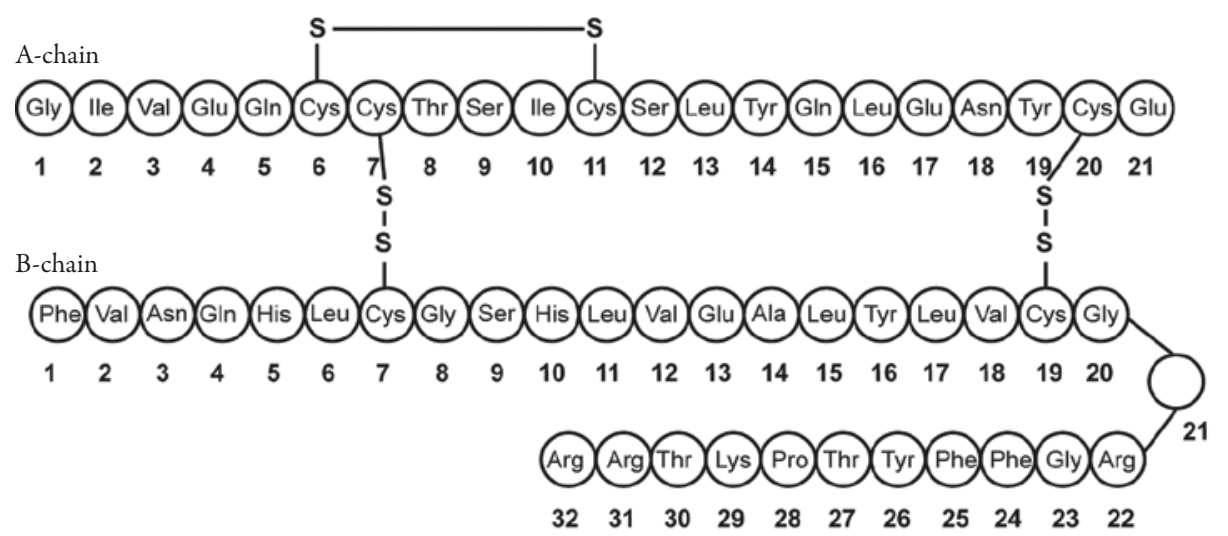

(b)

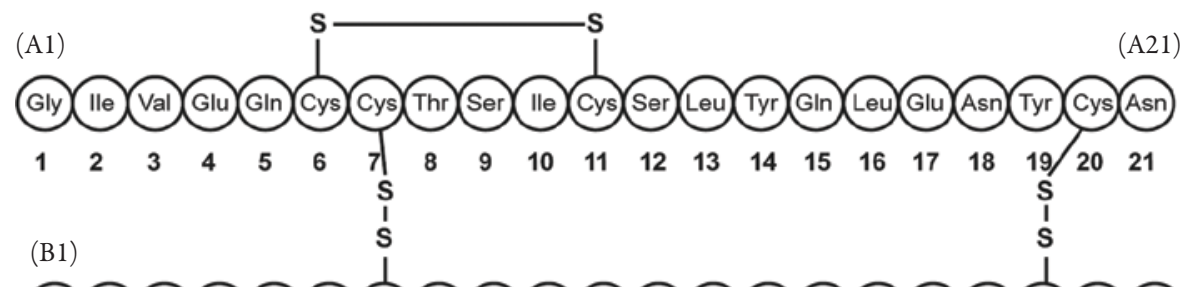

(A21)

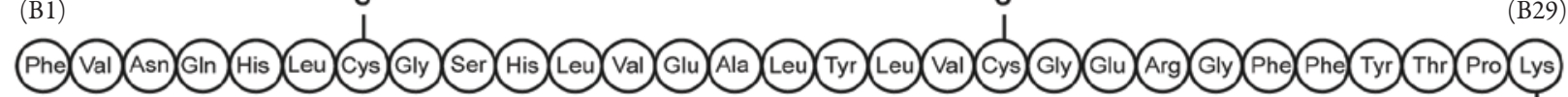

$\begin{array}{lllllllllllllllllllllllllllll}1 & 2 & 3 & 4 & 5 & 6 & 7 & 8 & 9 & 10 & 11 & 12 & 13 & 14 & 15 & 16 & 17 & 18 & 19 & 20 & 21 & 22 & 23 & 24 & 25 & 26 & 27 & 28 & 29\end{array}$

(c)

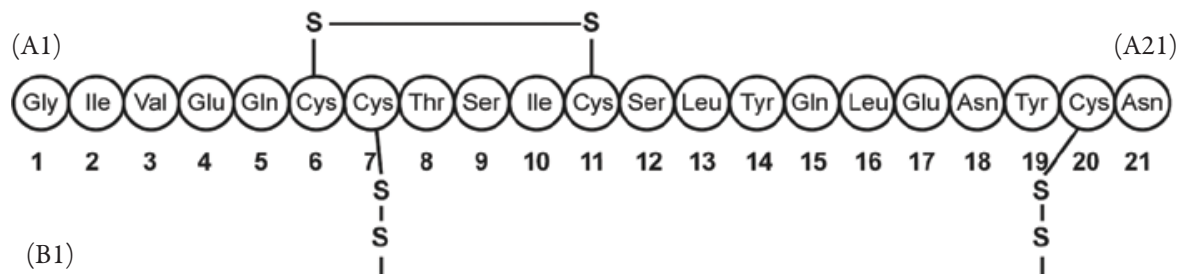

(A21)

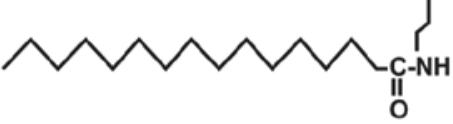

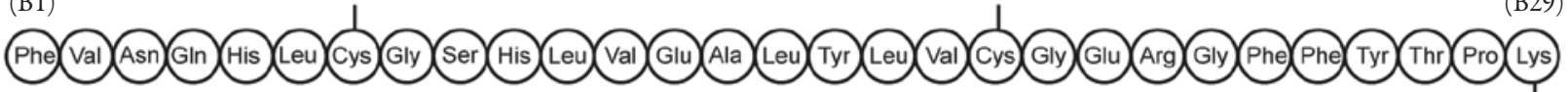

$\begin{array}{lllllllllllllllllllllllllllll}1 & 2 & 3 & 4 & 5 & 6 & 7 & 8 & 9 & 10 & 11 & 12 & 13 & 14 & 15 & 16 & 17 & 18 & 19 & 20 & 21 & 22 & 23 & 24 & 25 & 26 & 27 & 28 & 29\end{array}$

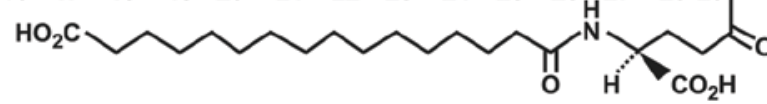

Fig. 4 Molecular structure of long-acting insulin analogs - (a) insulin glargine, (b) insulin detemir, and (c) insulin degludec [50]. Reprinted from Diabetes Technology and Therapeutics, Vol. 13, Supplement 1, Owens DR, "Insulin preparations with prolonged effect," p. S8, 2011, with permission from Mary Ann Liebert, Inc. publishers 
to dimers, which are further resolved into the absorbable monomer form. Among bolus insulin types, substitutions in this region can aid rapid absorption [49]. These substitutions include the reversal of the natural sequences of proline at position B28 and lysine at position B29 in insulin lispro (Fig. 3b), the natural sequences of proline at position B28 substituted by aspartic acid in insulin aspart (Fig. 3c), and the natural sequence of asparagine at position B3 substituted by lysine and glutamic acid instead of lysine at position B29 (Fig. 3d) in insulin glulisine [49]. The insulin molecules of basal analogs also have modifications at B30. In particular, insulin glargine (Fig. 4a) has elongation of the $\mathrm{C}$ terminus of the $\mathrm{B}$ chain, two arginine residues inserted at position B30, and replacement of asparagine with glycine at position A21, while insulin detemir (Fig. 4b) is produced by deleting the amino acid threonine at B30 of human insulin molecules and adding a myristic fatty acid residue to the $\varepsilon$-amino group of the lysine residue at B29 [50]. The newer long-acting insulin analog degludec has an insulin amino acid sequence that matches human insulin except $\mathrm{Thr}^{\mathrm{B} 30}$ is deleted and a 16-carbon fatty diacid is attached to Lys ${ }^{\mathrm{B} 29}$ with a glutamic acid spacer (Fig. 4c) [50]. Insulin analog premixes have also been developed to minimize patient error when combining insulins and to provide basal and bolus coverage in one injection; however, premixes might not provide optimal glycemic control for all patients due to the fixed ratio of their components [48].

\section{PK/PD of Basal, Bolus, and Insulin Analog Premixes}

\section{Long-Acting Insulin Analogs More Closely Mimic Physiologic Basal Insulin Secretion}

Basal analogs (Fig. 4 [50]) were designed to provide consistent, flat, long-acting insulin levels to mimic the constant release of insulin that regulates endogenous glucose output [48]. Two basal insulin analogs, insulin glargine and insulin detemir, are currently available [48]. In solution, insulin glargine has an acidic $\mathrm{pH}(\mathrm{pH} 4)$ and upon subcutaneous injection the acidic solution becomes neutralized thereby forming microprecipitates. This contributes to the slow release of insulin glargine into the circulation [48]. With insulin detemir, acylation of the molecule gives it a high binding affinity for albumin, which delays its absorption [50]. In solution, insulin detemir has a neutral physiologic $\mathrm{pH}$ (pH 7.4) and its hexamer-forming abilities together with its reversible albumin binding result in prolonged insulin action [51]. Both insulin detemir and insulin glargine exhibit prolonged (up to 24 hours) duration of action [52, 53] and little peak activity compared to NPH (Fig. 2 [41]) [54, 55], but the duration of action for insulin detemir can be as short as 5.7 hours and the duration of action can be as short as 10.8 hours for insulin glargine $[52,53]$. Plank and colleagues found that at a dose of $0.4 \mathrm{U} / \mathrm{kg}$, insulin detemir achieved maximal action at 8-10 hours with a mean end of action of almost 22 hours [56]. In addition, in patients with type 2 diabetes, Klein et al. found that the duration of action was dose-dependent and similar for both insulin glargine and insulin detemir [57]. Based on these findings, it is apparent that the majority of type 2 patients can be dosed once daily with these basal analogs, highlighting the benefit of these analogs over NPH, which was once considered long acting. Basal insulin analogs have also resolved the noticeable peak associated with NPH, bringing them closer to a physiologic basal insulin. However, some patients may require twice-daily dosing for both insulin detemir and insulin glargine as the duration of action may not cover 24 hours in all patients. Also, among patients with type 2 diabetes, time-action profiles of insulin detemir and insulin glargine 
administered at $0.4,0.8$, and $1.4 \mathrm{U} / \mathrm{kg}$ as part of a pharmacokinetic glucose clamp study were found to be similar, showing duration of action increased with rising doses and started declining between 16 and 18 hours for all doses [57]. At the two lower doses, the duration of action was estimated to be below 24 hours. The authors note that this pharmacokinetic study should not be extrapolated to clinical response [57]. Furthermore, some healthcare providers split doses. On balance, true basal coverage for all patients has not yet been fully achieved [4].

\section{Rapid-Acting Insulin Analogs Add to Patient Convenience}

In response to the shortcomings of the PK/PD profiles of RHI, which include a slow onset of action, a peak effect 3 hours after dosing, and a duration of action beyond 8 hours, three rapidacting bolus insulin analogs have been developed to date: insulin glulisine, insulin lispro, and insulin aspart [58]. All three analogs have a rapid onset of action (within 30-60 minutes) and a peak action within 2 hours, compared with the onset of action of 45-60 minutes and peak effect of 3 hours after RHI dosing (Fig. 2 [41]) [6, 10, 58, 59]. Whereas RHI must be given more than 30 minutes before meals, rapid-acting insulin analogs can be given just before a meal or even after the meal has begun. In a study involving type 1 diabetes patients treated with basal-bolus therapy, patients assigned to insulin aspart as their bolus therapy indicated a greater degree of flexibility compared to patients using RHI [60]. The inconvenience of insulin administration plays a large part in nonadherence to insulin regimens [48]. Because they have a more convenient administration schedule, bolus insulin analogs may improve patient adherence to prescribed treatments.

Insulin lispro was the first rapid-acting bolus insulin analog developed. The inversion of the lysine of B29 and the proline of B28 of human insulin allows insulin lispro to dissociate rapidly into monomers and become quickly absorbed into the circulation [2]. As an alternative approach, the structure of insulin aspart prevents self-association into insulin dimers and hexamers, which increases the rate of absorption of the insulin monomers into the blood $[49,61]$. For insulin glulisine, the amino acid alteration at positions B3 and B29 provides molecular stability and lowers the isoelectric point of insulin glulisine ( $\mathrm{pH}$ 5.1) compared to RHI ( $\mathrm{pH}$ 5.5), enhancing insulin glulisine's solubility at a physiologic $\mathrm{pH}[49,62]$. Unlike other bolus insulin analogs, insulin glulisine does not contain the hexamer-promoting zinc, allowing for immediate bioavailability at the injection site [49].

Insulin lispro, insulin aspart, and insulin glulisine have similar PK/PD properties and show low intrasubject variability. In general, all rapid-acting analogs achieve twice the maximal concentration and take about half the time to reach maximal concentration compared to equivalent doses of RHI [6, 10, 63-65]. The faster and more intense action of the insulin analogs more closely mimics endogenous insulin response, which can lead to better control of PPG levels compared to RHI $[6,66]$. In contrast to RHI, there is no delay in peak as the dose and depot increase. One study found that with a dose of $10 \mathrm{U}$ of insulin lispro, the mean peak insulin action was $99 \pm 39$ minutes, as compared with $179 \pm 93$ minutes for RHI $(P<0.05)$ [10]. For insulin aspart, Mudaliar et al. reported that the time to peak insulin action was $94 \pm 46$ minutes compared to $173 \pm 62$ minutes for RHI $(P<0.001)[6]$. Another study found that in healthy subjects, insulin aspart was absorbed twice as quickly and reached more than double the serum concentrations compared to RHI [67]. Also, both insulin glulisine and insulin lispro had more rapid-acting profiles than RHI in a study involving 18 subjects without diabetes [63]. 


\section{Insulin Analog Premixes}

Insulin analog premixes are fixed-ratio combinations of bolus and intermediate-acting insulins that were developed to simplify the insulin regimen and to minimize patient selfmixing error. However, as adjustments of either the bolus or basal component alone are not possible, self-mixing still may provide slightly better glucose control for some patients [48]. Because the long-acting analogs detemir and glargine cannot be mixed with other insulins, the insulin included in analog premixes is normally an intermediate-acting agent such as a protamine aspart or lispro protamine suspension, obviating the clinician's ability to utilize the advances made in the development of the long-acting insulin analogs. Insulin analog premixes that are currently available in North America and Europe include a 70/30 insulin aspart protamine/insulin aspart mixture (BIAsp 30), a 75/25 insulin lispro protamine/ insulin lispro mixture (Mix 25), and a 50/50 insulin lispro protamine/insulin lispro mixture (lispro 50/50). Lispro 50/50 is used much less frequently than either BIAsp 30 or Mix 25 [68]. Although both biphasic human insulin 70/30 (BHI 30) and analog premixes contain a mixture of intermediate and short-acting insulins, analog premixes have more physiologic pharmacokinetic profiles and provide better PPG control than RHI premixes [69]. For example, BIAsp 30 produces a higher peak insulin level in the circulation more rapidly than BHI 30. In a study comparing the pharmacology of BHI 30, BIAsp 30, and Mix 25, maximal serum insulin concentration $\left(\mathrm{C}_{\max }\right)$ was twofold higher with BIAsp 30 than with BHI $30(P<0.001)$ and time to $\mathrm{C}_{\max }$ was 55 minutes shorter $(P<0.001)$ [70]. $\mathrm{C}_{\max }$ was also significantly higher in patients given Mix 25 compared to those given BHI 30, although the $\mathrm{C}_{\max }$ was $12 \%$ higher for BIAsp 30 than for Mix 25 (not statistically significant) [70].
In healthy male subjects who received a single injection of $0.3 \mathrm{U} / \mathrm{kg}$, BIAsp 30 had a significantly greater metabolic effect than BHI 30 [71]. To add to this, Heise et al. showed that BIAsp 30 had earlier and greater activity compared to BHI 30 in patients with type 2 diabetes [72]. Taken together, these attributes of BIAsp 30 translate into low PPG values postinjection. Finally, dosing is more convenient with insulin analog premixes than with RHI premixes. While an injection-meal interval of at least 30 minutes is recommended when using conventional human premixed insulin, patient adherence to this recommendation is low. Newer insulin analog premixes (e.g., BIAsp 30), which are absorbed rapidly from the subcutis, can be injected immediately before eating or even after the start of a meal [69].

\section{Safety}

\section{Rapid-Acting (Bolus) Insulin Analogs Reduce Nocturnal Hypoglycemia, but not Severe}

\section{Hypoglycemia}

Hypoglycemia is a major concern for patients with diabetes and is divided into three different categories: minor (nonsevere) hypoglycemia, severe hypoglycemia, and nocturnal hypoglycemia. However, according to the American Association of Clinical Endocrinologists (AACE), hypoglycemia can be difficult to assess as there is no consensus as to what constitutes low plasma glucose levels [73]. While symptoms of severe hypoglycemia are generally recognizable, mild-to-moderate hypoglycemia may remain asymptomatic and unreported. The American Diabetes Association (ADA) Workgroup on Hypoglycemia further characterizes hypoglycemia as severe hypoglycemia, documented symptomatic hypoglycemia, asymptomatic hypoglycemia, probable symptomatic hypoglycemia, and relative hypoglycemia (Table 1) [74]. It is also important to 
Table 1 ADA Workgroup on Hypoglycemia: classification of hypoglycemia in people with diabetes [74]

\begin{tabular}{|c|c|}
\hline Classification & Description \\
\hline Severe hypoglycemia & $\begin{array}{l}\text { An event requiring assistance of another person actively to administer } \\
\text { carbohydrate, glucagon, or other resuscitative actions. Plasma glucose } \\
\text { measurements may not be available during such an event, but neurological } \\
\text { recovery attributable to the restoration of plasma glucose to normal is } \\
\text { considered sufficient evidence that the event was induced by a low plasma } \\
\text { glucose concentration. }\end{array}$ \\
\hline Documented symptomatic hypoglycemia & $\begin{array}{l}\text { An event during which typical symptoms of hypoglycemia are accompanied } \\
\text { by a measured plasma glucose concentration } \leq 3.9 \mathrm{mmol} / \mathrm{L} \text {. }\end{array}$ \\
\hline Asymptomatic hypoglycemia & $\begin{array}{l}\text { An event not accompanied by typical symptoms of hypoglycemia but with } \\
\text { a measured plasma glucose concentration } \leq 3.9 \mathrm{mmol} / \mathrm{L} \text {. }\end{array}$ \\
\hline Probable symptomatic hypoglycemia & $\begin{array}{l}\text { An event during which symptoms typical of hypoglycemia are not } \\
\text { accompanied by a plasma glucose determination but that was presumably } \\
\text { caused by a plasma glucose concentration } \leq 3.9 \mathrm{mmol} / \mathrm{L} \text {. }\end{array}$ \\
\hline Relative hypoglycemia & $\begin{array}{l}\text { An event during which the person with diabetes reports any of the } \\
\text { typical symptoms of hypoglycemia and interprets those as indicative of } \\
\text { hypoglycemia, with a measured plasma glucose concentration } \\
>3.9 \mathrm{mmol} / \mathrm{L} \text { but approaching that level. }\end{array}$ \\
\hline
\end{tabular}

note that defects in the glucose counterregulatory response, including a lack of both decreased insulin and increased glucagon and an attenuated epinephrine response, in patients with type 1 diabetes, can cause hypoglycemia unawareness. Among patients with type 1 diabetes, glucagon response to hypoglycemia is usually blunted within 1-5 years of onset of the disease, and is usually absent within $15-30$ years [75, 76]. Among patients intensively treated with insulin and those newly diagnosed with type 1 , the loss of glucagon responses during periods of hypoglycemia may be due to "hypoglycemia-associated autonomic failure" $[75,77]$. As type 2 diabetes progresses and the duration of insulin use lengthens, hypoglycemia, including the asymptomatic variety, becomes more frequent [78-80]. This loss of warning symptoms obviates any opportunity for the patient to take corrective action [74]. Therefore, even minor hypoglycemic events may impair the ability of a patient to recognize the hypoglycemic symptoms.
Severe hypoglycemia has the generally accepted definition of requiring the assistance of another person [74]. Nocturnal hypoglycemia may occur during the time period after a bedtime injection and before eating breakfast or the administration of any oral antihyperglycemic agent in the morning; this type of hypoglycemia is the one most feared by patients. Hypoglycemia was very prevalent before the development of insulin analogs and continues to be ever present and a clinical challenge even with the advances in hypoglycemic management afforded by analogs. According to one meta-analysis, a significant reduction in the risk of nocturnal hypoglycemia was associated with insulin aspart treatment compared with RHI treatment (relative risk [RR] 0.67; 95\% CI 0.54-0.83), although no difference in severe hypoglycemia was reported [81]. Brunetti et al. also found a similar and low rate of severe nocturnal hypoglycemia in patients treated with either insulin lispro or RHI in addition to basal 
insulin glargine [82]. Rapid-acting insulin analogs can thus decrease rates of nocturnal hypoglycemia but no difference has been found in rates of severe hypoglycemia between rapid-acting insulin and RHI.

\section{Basal Insulin Analogs Reduce the Incidence of Hypoglycemia}

Several studies indicate that the risk of nocturnal hypoglycemia is reduced by using basal insulin analogs as compared to NPH. In a study by Riddle and colleagues, patients with type 2 diabetes who were already on oral therapy were randomly assigned to either insulin glargine or NPH [83]. Rates of nocturnal hypoglycemia and other symptomatic hypoglycemia were lower with insulin glargine. In addition to the demonstrated reduction in the rates of hypoglycemia, cardiovascular safety has been a question with regard to exogenous insulin use. The results of the long-term Insulin Glargine (rDNA Origin) Injection versus Pioglitazone as add-on Therapy in Patients Failing Monotherapy With Sulfonylurea or Metformin (ORIGIN) study demonstrated that after a median follow-up period of 6.2 years, when used to treat FPG, insulin glargine was found to have a neutral effect on cardiovascular outcomes [84]. In an analysis of multiple studies comparing insulin detemir with NPH in type 1 diabetes, the risk reduction for nocturnal hypoglycemia was reported to be approximately 30\%. Rate reductions are even greater for patients with type 2 diabetes [85-87]. Reductions in hypoglycemia may be related in part to insulin detemir's reduced glycemic variability, or to the lack of an insulin peak when compared with NPH. Pieber et al. compared once-daily insulin glargine and twice-daily insulin detemir in patients with type 1 diabetes and found that the overall risk of hypoglycemia was similar after the administration of either insulin [3]. However, the risks of both severe and nocturnal hypoglycemia were significantly lower with insulin detemir than with insulin glargine (72\% and 32\% reduction, respectively, $P<0.05$ ). Therefore, insulin detemir may be more effective in reducing nocturnal hypoglycemia than insulin glargine in patients with type 1 diabetes, but further studies are needed to clarify this.

\section{Insulin Analog Premixes Reduce Hypoglycemia in Certain Patient Populations}

A systematic review comparing insulin analog premixes (BIAsp 30, Mix 25, lispro 50/50) with RHI premixes found that the overall hypoglycemia risk was similar for many populations of patients with type 2 diabetes [88]. However, several noninferiority studies found hypoglycemic benefits of analog premixes compared to RHI premixes in patients under more challenging glucometabolic conditions [88]. Clinical studies have yielded variable results regarding the risk of hypoglycemia following the administration of BIAsp 30. In one meta-analysis, rates of overall hypoglycemia were not significantly different between BIAsp 30 and BHI 30 in patients with type 2 diabetes [89]. However, in the same study, the rate of nocturnal hypoglycemia was 50\% lower for BIAsp 30 than for BHI 30 (rate ratio 0.50; 95\% CI 0.38-0.67; $P<0.01$ ). In addition, for BIAsp 30 , the likelihood of major hypoglycemia was significantly lower compared to BHI 30 (odds ratio 0.45 ; 95\% CI $0.22-0.93 ; P<0.05)$. In this study, the rate of daytime hypoglycemia was 24\% lower with BHI 30 than BIAsp 30 (rate ratio $1.24 ; 95 \%$ CI $1.08-1.43 ; P<0.01$ ) [89]. In another study, the incidence ratio for reported hypoglycemia for BIAsp 30 was significantly lower compared with BHI 30 in insulin-naive type 2 diabetes patients $(0.74 ; 95 \%$ CI $0.62-$ 0.89; $P=0.001)$, but in other patients, the difference in reported hypoglycemia was not significant between BIAsp 30 and BHI 30 [90]. 
In the Observational Study of Safety and Effectiveness of NovoMix ${ }^{\circledR} 30$ (Biphasic Insulin Aspart) for the Treatment of Diabetes Mellitus (IMPROVE) observational study of patients with type 2 diabetes, major hypoglycemia was reduced in insulin-naive patients who started on BIAsp 30 and in those who switched to BIAsp 30 from another insulin [91]. These data suggest that insulin analog premixes can reduce the risk of nocturnal and major hypoglycemia in patients with type 2 diabetes and overall hypoglycemia in certain patient populations.

\section{Efficacy/Variability}

\section{Bolus Insulin Analogs Improve Glycemic Control}

Several studies have found that rapid-acting insulin analogs provide better glycemic control than RHI or NPH. A meta-analysis of 13 studies found that in patients with type 1 diabetes, $\mathrm{HbA}_{1 \mathrm{c}}$ levels were lower with insulin aspart than with RHI [81]. For patients with type 2 diabetes, PPG was significantly lower in the insulin aspart group than in the RHI group in nine studies [81]. In addition, insulin lispro and insulin aspart are more effective than RHI in lowering $\mathrm{HbA}_{1 \mathrm{c}}$ levels in patients who receive continuous subcutaneous infusion of insulin $[92,93]$. An analysis of noninferiority, randomized, controlled trials obtained via a search of PubMed and congress proceedings showed that rapid-acting insulin analogs (insulin glulisine, insulin aspart, and insulin lispro) were either noninferior to or provided greater improvements in glycemic control than RHI in a basal-bolus regimen [94]. All of the trials in this analysis were designed to be noninferiority trials according to US Food and Drug Administration (FDA) guidance for diabetes studies. Rapid-acting insulin analogs are clinically superior and are recommended by AACE and the ADA instead of RHI because they cause less hypoglycemia [73, 95].

\section{Basal Insulin Analogs Improve Glycemic Control}

Both insulin glargine and insulin detemir have shown similar improvement in $\mathrm{HbA}_{1 \mathrm{c}}$ and FPG levels compared with NPH [68]. However, treatment with insulin glargine resulted in less intersubject variability in the rates of glucose infusion needed to maintain proper glycemic levels compared to the intersubject variability in rates of glucose infusion for NPH [96]. In addition, in a randomized, open-label trial involving 595 patients with type 1 diabetes, glycemic control was improved with an insulin detemir/ insulin aspart combination compared with $\mathrm{NPH} / \mathrm{RHI}\left(\mathrm{HbA}_{1 \mathrm{c}} 7.8 \%\right.$ vs. $\left.8.11 \%, P<0.001\right)$ [97]. Intrapatient daily variation in plasma glucose was also lower with insulin detemir/insulin aspart than with NPH/RHI [97]. Taken together, these results suggest that insulin glargine and insulin detemir are more effective for glycemic control than NPH.

\section{Insulin Analog Premixes}

Studies have shown that insulin analog premixes BIAsp 30 and Mix 25 provide $\mathrm{HbA}_{1 \mathrm{c}}$ control to a similar extent as BHI 30 [71]. In a study involving patients with type 2 diabetes, BIAsp 30 provided better PPG control compared with either BHI 30 or Mix 25 [92]. Mix 25 also limited PPG excursions more effectively than did BHI 30 in a pharmacodynamic study [68]. BIAsp 30 was associated with improved $\mathrm{HbA}_{1 \mathrm{c}}$ levels compared with $\mathrm{BHI} 30$ in insulin-naive patients with type 2 diabetes, type 1 diabetes patients, or insulinexperienced patients with type 2 diabetes [90]. In addition, while the analog premixes can be given three times a day, RHI premixes cannot. A study by Heise et al. showed that glucose infusion rates for BIAsp 30 approximated basal bolus with three injections [72]. Analog premixes may thus be a more effective choice than human premixes for some patients. 


\section{HIGH CONCENTRATION INSULIN}

\section{U-500 Regular Insulin}

Severe insulin resistance is a condition in which a patient with diabetes requires more than 200 units of insulin daily. Obesity is one of the most common causes of insulin resistance [98]. Severe insulin resistance is difficult to treat successfully, and to achieve good glycemic control in this patient population, large doses of insulin are required daily, which can result in leakage and poor absorption. Moreover, large-volume injection may cause discomfort and, consequently, poor compliance [99]. The need for high insulin concentration was evident and this need prompted the development of U-500 regular insulin.

Bovine U-500 regular insulin (Iletin; Eli Lilly and Company, Indianapolis, Indiana, USA) was first introduced in the USA in 1952. The current recombinant human regular U-500 (U-500R) insulin preparation (Humulin R U-500; Eli Lilly and Company), which is available in 500 units $/ \mathrm{mL}$, became available in the USA in 1997. U-500 regular insulin is fivefold more concentrated than U-100 regular insulin and, thus, the administration of 100 units of U-500 requires an injection volume of $0.2 \mathrm{~mL}$ compared with $1 \mathrm{~mL}$ for U-100 regular insulin. The smaller injection volume plays a role reducing the potential of leakage and increasing the potential for absorption [100]. Use of U-500R increased significantly in recent years, reflecting the increasing number of patients requiring high insulin doses. A randomized, double-blind, crossover euglycemic clamp study compared the pharmacokinetics and pharmacodynamics of single subcutaneous injections of 50 and 100 unit doses of U-500R and U-100R in healthy obese subjects [101]. Both formulations produced relatively long durations of action (18.3-21.5 hours). Time to peak concentration and time to maximum effect were significantly longer for U-500R than U-100R at the 100 unit dose $(P=0.05)$. Time variables reflective of duration of action (late $\mathrm{tR}_{\max 50}, \mathrm{tR}_{\text {last }}$ ) favored U-500R at both doses $(P=0.05)$. The authors of this study and the authors of a similar study concluded that subcutaneous injection of U-500R insulin was similar to U-100R insulin; however, U-500R, peaks of concentration and action profiles were blunted and the effect after the peak was prolonged $[98,101]$.

Statistical analysis of eight clinical studies conducted on U-500 regular insulin was performed by Lane et al. and showed significant reductions in $\operatorname{HbA}_{1 \mathrm{c}}(P \leq 0.001)$ and increases in weight $(P=0.002)$ [100]. These results are similar to that typically observed with U-100 insulin therapy. Nonsignificant increases in total insulin dose were observed in the 3-98 months after patients were switched to U-500 regular insulin administered either by subcutaneous injection or by continuous subcutaneous insulin infusion [100]. Lowery et al. investigated the changes in $\mathrm{HbA}_{1 \mathrm{c}}$, weight, and total daily insulin dose (TDD) following the initiation of insulin U-500 alone or as part of a basal/bolus insulin regimen [102]. The study showed reductions in $\mathrm{HbA}_{1 \mathrm{c}}(9.5 \%$ at baseline vs. $7.7 \%$ at $6-9$ months, $P<0.0001)$ and increases in weight (128.8-32.7 vs. $131.5-31.3 \mathrm{~kg}$, $P<0.014)$ and TDD (260-111 to 333-106 units/ day, $P<0.0002)$. The authors concluded that $\mathrm{U}-500$ resulted in improvements in $\mathrm{HbA}_{1 \mathrm{c}}$ and weight gain and increased TDD when used alone or as part of combination insulin therapy [102].

\section{INVESTIGATIONAL INSULINS AND THE FUTURE OF INSULIN THERAPY}

The development of insulin analogs improved glycemic control and reduced nocturnal hypoglycemia, but further improvements are 
still necessary. While current basal insulin analogs have advantages over NPH, these analogs still do not have a completely flat profile, and do not achieve 24-hour insulin coverage in all patients [103]. Although hypoglycemia is reduced with insulin analog treatment, it remains an important limitation that can lead to increased food intake and decreased insulin dosage, with patients ultimately not meeting their fasting targets [104]. Unrecognized hypoglycemia, including nocturnal hypoglycemia, can be particularly dangerous. A major goal of investigational insulin therapies is to provide optimal basal insulin coverage that mimics the physiologic insulin secretion profile. Flexibility and convenience in dosing regimens and insulin administration techniques are also important factors to consider in the development of next-generation insulins.

\section{Ultra-Long-Acting Basal Insulin}

Insulin degludec, the only ultra-long-acting basal insulin, is currently in phase 3 development (Fig. 4 [50]) [105]. The method of protraction involves the slow release of insulin degludec monomers from the multihexamers that only form after subcutaneous injection, resulting in an ultra-long duration of action over 42 hours, a long half-life ( $>24$ hours), and a smooth and stable pharmacokinetic profile at steady state $[104,106]$. These multihexamers also provide a buffer against changes in absorption rate, which contributes to the stable and consistent pharmacokinetic profile [104]. The half-life of a drug is particularly important when evaluating the potential for accumulation. Because plasma concentration decreases by $50 \%$ for each half-life [107], matching dosing frequency with the half-life of a long-acting basal insulin can reduce the risk of inappropriate stacking. Once a steady state is reached, the amount of insulin eliminated over a 24-hour period will equal the amount injected.
The formation of multihexamers is the primary differentiator in the protraction of effect between the current basal insulin analogs and insulin degludec. A phase 1 trial comparing the pharmacokinetic profile of insulin degludec to insulin glargine found that degludec had a twofold longer half-life and a more stable pharmacokinetic profile with minimal fluctuations [108]. Oneyear results from two phase 3 treat-to-target trials investigating the noninferiority and safety of insulin degludec $[109,110]$ have shown similar efficacy between insulin degludec once daily and insulin glargine once daily in patients with type 1 or type 2 diabetes. In type 1 diabetes patients, overall glycemic control was improved as evidenced by a $0.4 \%$ reduction in $\mathrm{HbA}_{1 \mathrm{c}}$ for patients on insulin degludec or insulin glargine and a similar proportion of subjects achieving $\mathrm{HbA}_{1 \mathrm{c}}$ less than 7\% [109]. In type 2 diabetes patients on basal-bolus therapy with insulin aspart as the bolus insulin, insulin degludec improved overall glycemic control at comparable rates to insulin glargine, and in both treatment groups $\mathrm{HbA}_{1 \mathrm{c}}$ less than $7 \%$ was reached in $49 \%$ of subjects [110]. In addition, insulin degludec and insulin glargine reduced FPG by $1.3 \mathrm{mmol} / \mathrm{L}$ and $1.44 \mathrm{mmol} / \mathrm{L}$, respectively, in type 1 diabetes patients [109], and by $2.3 \mathrm{mmol} / \mathrm{L}$ and $2.0 \mathrm{mmol} / \mathrm{L}$, respectively, in type 2 diabetes patients [110]. As these were treat-to-target trials with FPG as the titration target, differences in $\mathrm{HbA}_{1 \mathrm{c}}$ and FPG were not expected between insulin degludec and insulin glargine in either trial. Rates of nocturnal confirmed hypoglycemia (plasma glucose $<3.1$ $\mathrm{mmol} / \mathrm{L}$ or severe episodes as per ADA definition) were $25 \%$ lower with insulin degludec (4.4 vs. 5.9 episodes/patient year [109] and 1.4 vs. 1.8 episodes/patient year [110]) compared with insulin glargine in both studies. Another trial evaluated the noninferiority of insulin degludec dosed once daily in a flexible regimen (degludec flex) compared to insulin glargine given according 
to the FDA-approved prescribing information once daily at the same time each day, with time of day decided by the physician and patient [111]. The flexible regimen involved a forced rotation of insulin degludec dosing between morning and evening, resulting in 8-40 hour dosing intervals. At 26 weeks, insulin degludec flex and insulin glargine once daily reduced $\mathrm{HbA}_{1 \mathrm{c}}$ by $1.28 \%$ and $1.26 \%$, respectively, confirming the noninferiority of insulin degludec flex compared to insulin glargine. For insulin degludec flex, the mean FPG at 26 weeks was significantly lower compared to insulin glargine once daily. Even with this extreme range in dosing times (8-40 hours between doses) rates of confirmed hypoglycemia (3.6 episodes with degludec vs. 3.5 episodes with glargine) and nocturnal hypoglycemia ( 0.6 episodes with degludec vs. 0.8 episodes with glargine) were similar between the insulin degludec flex and insulin glargine groups, indicating that insulin degludec can be injected whenever convenient for the patient without compromising glycemic control [111]. A phase 1 trial comparing the pharmacokinetic profile of insulin degludec to insulin glargine found that insulin degludec had a half-life of 25.4 hours compared to only 12.5 hours for insulin glargine [108]. That study showed a consistent and flat profile as evidenced by the equal distribution of serum exposure to insulin degludec between the first and second 12 hours post-dosing and no stacking [108]. While the long duration of action of insulin degludec may raise concerns for hypoglycemia, several phase 3 clinical studies of insulin degludec have demonstrated a low risk of hypoglycemia, specifically nocturnal hypoglycemia, compared with insulin glargine [109-111]. In addition, results are promising from phase 2 trials combining two analogs, insulin degludec with insulin aspart [103, 112, 113]. One 16-week, treat-to-target, open-label trial evaluated the safety and efficacy of insulin degludec (70\%)/insulin aspart (30\%) (IDegAsp) compared to BIAsp 30 both dosed twice daily in patients with type 2 diabetes [112]. The rate of confirmed hypoglycemia was 58\% lower for IDegAsp than for BIAsp 30, while the mean FPG was $0.98 \mathrm{mmol} / \mathrm{L}$ lower for IDegAsp than for BIAsp 30 . In another phase 2 trial comparing IDegAsp to insulin glargine in a 16-week, open-label trial in patients with type 2 diabetes, a similar number of patients achieved an $\mathrm{HbA}_{1 \mathrm{c}}$ less than $7.0 \%$ in the last 4 weeks of treatment without any confirmed hypoglycemia [103]. Although mean FPG was similar for IDegAsp and insulin glargine, mean plasma glucose levels 2-hours post-dinner were lower for IDegAsp $(0.13 \mathrm{mmol} / \mathrm{L})$ than for insulin glargine $(1.63 \mathrm{mmol} / \mathrm{L})$. A phase 3, treat-to-target, 26-week, open-label trial compared IDegAsp dosed once daily at any meal with insulin aspart at the remaining meals to insulin detemir with insulin aspart at all meals in patients with type 1 diabetes [113]. $\mathrm{HbA}_{1 \mathrm{c}}$ improved and FPG decreased to similar levels in both groups. Rates of confirmed hypoglycemia were similar for both IDegAsp and insulin detemir, but rates of nocturnal confirmed hypoglycemia were 37\% lower for IDegAsp than insulin detemir. It is noteworthy that this is the first and only insulin analog premix in which each insulin retains its individual characteristics.

\section{U-200 Insulin}

Insulin degludec is being developed in both $100 \mathrm{U} / \mathrm{mL}$ and $200 \mathrm{U} / \mathrm{mL}$ (U-100 and U-200) formulations for once-daily use in all patients with diabetes. U-100 covers the insulin requirements for many patients, whereas U-200 specifically benefits patients who require more than $80 \mathrm{U}$ of basal insulin per injection, which is the dose limitation with currently available insulin delivery devices; 160 U of U-200 can be administered in a single injection using a newly developed prefilled pen. The PK/PD properties 
of U-200 dosed at $0.6 \mathrm{U} / \mathrm{kg}$ in subjects with type 2 diabetes ( $n=16$, mean: body mass index, $30 \mathrm{~kg} / \mathrm{m}^{2} ; \mathrm{HbA}_{1 \mathrm{c}}, 7.3 \%$ ) who received U-200 once daily over 6 days were studied [114]. The glucose-lowering effect of U-200 was shown to be evenly distributed over the dosing interval. The effect of insulin degludec extended beyond 26 hours in all subjects, as blood glucose stayed close to the target level throughout the clamp, and the terminal half-life at steady state was 26.2 hours. Finally, U-200 was well tolerated and safe, with no injection site reactions. The authors concluded that U-200 has a flat and stable glucose-lowering effect with a duration of action beyond 26 hours in people with type 2 diabetes. The bioequivalence (post-hoc analysis) between both U-100 and U-200 was studied in a randomized, double-blind, two-period crossover, and multiple-dose study in 33 subjects with type 1 diabetes. The study demonstrated that the two concentrations of insulin degludec were bioequivalent and had a similar total glucose-lowering effect. Because the glucoselowering effect and pharmacokinetic exposure were evenly distributed across a 24-hour dosing interval for both concentrations, the study investigators suggested that U-100 and U-200 can be used interchangeably in clinical practice. The study also suggested that the availability of U-200 could increase the number of patients with type 2 diabetes who can rely on a single basal insulin injection daily to meet their 24-hour insulin requirements [115].

\section{Long-Acting Insulin Lispro}

The long-acting insulin LY2605541 (LY) in development is a PEGylated version of insulin lispro, which has been designed to have a large hydrodynamic size to delay insulin absorption and to reduce its clearance and, consequently, result in prolonged duration of action.
Hypoglycemia and glucose variability were assessed in a subset of patients from a phase 2, randomized, open-label, parallel study of LY $(n=51)$ or insulin glargine $(n=25)$ [116]. At 12 weeks, LY-treated patients spent less time with interstitial glucose below $70 \mathrm{mg} / \mathrm{dL}$ than glargine-treated patients during the nocturnal period (11 \pm 5 vs. $38 \pm 13$ minutes, $P=0.024$ ) and during the 24 -hour period ( $25 \pm 6$ vs. $83 \pm$ 16 minutes, $P<0.001)$. Significantly fewer LY than glargine-treated patients experienced any hypoglycemia $(50.0 \%$ vs. $78.3 \%, P=0.036)$, including nocturnal hypoglycemia $(20.5 \%$ vs. $47.8 \%, P=0.027$ ); however, both treatments resulted in similar mean glucose values. LY-treated patients had significantly lower intraday glucose standard deviation at 12 weeks compared to glargine-treated patients for both nocturnal $(1.00 \pm 0.07$ vs. $1.35 \pm 0.16 \mathrm{mmol} / \mathrm{L}$, $P=0.061)$ and diurnal $(2.03 \pm 0.10$ vs. $2.50 \pm$ $0.18 \mathrm{mmol} / \mathrm{L}, P=0.039$ ) periods. The authors concluded that treatment with LY resulted in fewer patients with hypoglycemia and less time spent in hypoglycemia, as well as lower intraday glucose variability compared with treatment with glargine [116]. In addition, LY treatment resulted in weight loss [117].

\section{Inhaled Insulin}

Inhaled insulin delivery systems can provide a noninvasive alternative for patients with diabetes, and can be especially helpful for patients who are fearful of injections. Inhaled insulin can also circumvent the inconvenient regimen of multiple daily injections required by subcutaneous insulin therapies. Several inhaled insulin delivery systems have been developed, but much of the investigation in this area has been halted or postponed. Pfizer's Exubera was the first inhaled insulin to receive FDA approval in 2006. Although Exubera showed clinical 
efficacy in glycemic control and low risk of hypoglycemia [118, 119], it was pulled from the market due to poor uptake and acceptance by both patients and prescribers [120]. The $\mathrm{AER}_{\mathrm{x}}$ insulin diabetes management system of Novo Nordisk Inc. generates insulin droplets for pulmonary delivery. A randomized trial found that $\mathrm{AER}_{\mathrm{x}}$ inhaled insulin was noninferior to subcutaneous insulin in lowering $\mathrm{HbA}_{1 \mathrm{c}}$ levels, but the $\mathrm{AER}_{\mathrm{x}}$ system was associated with a higher risk of nocturnal hypoglycemia [121]. Further investigations of $\mathrm{AER}_{\mathrm{x}}$ have been discontinued [120]. Technosphere insulin (TI), another inhaled insulin, was compared in a randomized, open-label study to the efficacy and safety of subcutaneous RHI in covering prandial insulin needs. TI significantly improved PPG levels and had a more favorable PK/PD profile compared with subcutaneous RHI [122]. The TI system is currently undergoing phase 3 trials, and a placebo formulation has been developed for double-blind, placebo-controlled studies [120].

\section{Oral Insulin}

Oral insulin can provide a convenient method of administration, potentially leading to improved glycemic control for patients with poor adherence to subcutaneous insulin regimens. Physiological barriers of the gastrointestinal tract pose a major challenge for the optimal delivery of oral insulin [8]. Gut enzymes such as pepsin and trypsin break down insulin into its constituent amino acids, thereby abolishing insulin activity [8]. The tightly packed columnar cells and thick layer of mucin of the gastrointestinal tract create another barrier by preventing insulin absorption [8]. A major goal in the development of oral insulins is to bypass these natural defense mechanisms to allow for insulin entry into the gastrointestinal tract.
Several oral insulins are currently under investigation. IN-105, an oral insulin analog delivered in tablet form, was found to demonstrate a dose-dependent decrease in PPG in patients with type 2 diabetes [123]. Another oral insulin formulation with $4-\mathrm{CNAB}$ had a faster onset and shorter duration of action compared with subcutaneous RHI, but intersubject variability in absorption was relatively high [124]. In general, oral insulin is showing promising results in clinical trials and could improve patient satisfaction with insulin treatments.

\section{MITOGENIC ACTIVITIES OF INSULIN}

\section{Diabetes and Cancer Risk}

An increasing number of epidemiological studies have explored the relationship between diabetes and cancer. Patients with type 2 diabetes have an increased risk of mortality from various solid tumors, including colon, liver, pancreas, bladder, and female breast [125-131]. The association between diabetes and cancer is complicated by confounding variables, particularly metabolic syndrome, including obesity and insulin resistance [132, 133]. These comorbidities can independently increase the risk of certain cancers, such as hepatocellular, esophageal, and colon [134]. In addition, insulin therapy may influence the cancer risk associated with diabetes. For example, chronic insulin therapy increases the risk of colorectal cancer in patients with type 2 diabetes [135].

\section{Metabolic and Mitogenic Potential of Insulin Therapy}

Insulin therapy is an important and, often, a lifesaving therapy for patients with diabetes. The molecular mechanisms by which insulin and hyperinsulinemia, whether in cell culture or in vivo 
lead to mitogenicity are caused by the ability of insulin to bind to insulin receptor and, to a much lesser degree, to bind to insulin-like growth factor 1 (IGF-1) receptor [136]. Because the insulin receptor and IGF-1 receptor share $80 \%$ sequence of homology at the beta subunit and both receptors are members of the receptor tyrosine kinase family, insulin has the theoretical potential to induce a cell proliferation response. Potentiating the action of IGF-1 (epidermal growth factor, platelet derived growth factor, and vascular endothelial growth factor) by insulin has been observed in a variety of tissues, including vascular smooth muscle cells and breast cancer cells, among others [137-141]. Therefore, enhanced cellular responsiveness to growth factors is a physiological effect of insulin. This response becomes pathological in response to endogenous or exogenous hyperinsulinemia [142]. However, it is important to note that the clinical relevance and implications of insulin binding to the IGF-1 receptor are still not completely elucidated.

\section{Insulin Analogs and Cancer}

Insulin analogs are created by recombinant DNA technology in order to generate insulins with pharmacokinetic profiles that simulate the different phases of endogenous secretion of insulin. Several insulin analogs have been developed in recent years. Modification of the insulin molecule not only alters its metabolic effect, but it can also change its mitogenic potency [143]. A study of patients without known malignant disease who had received first-time therapy for diabetes exclusively with human insulin, aspart, lispro or glargine was conducted to study the effect of these insulin products on neoplasms [143]. The study showed a positive association between cancer and insulin dose for all insulin types. Glargine had a dose-dependent increase in cancer risk compared with human insulin $(P<0.0001)$, whereas lispro and aspart did not show an increased risk of cancer [143]. The relationships between insulin and cancer are not definitive and are often conflicting when a specific cancer and use of insulin were examined. Some studies have shown a positive correlation between insulin use and colorectal carcinoma [135, 144-146], pancreatic cancer [147], and liver cancer [148]. Other studies have shown no association between insulin therapy and pancreatic cancer [149] or prostate cancer [150]. The ORIGIN study, however, the first long-term study to assess this question, demonstrated a neutral effect on cancers after more than 6 years of insulin glargine use [84]. An inverse association was seen in one study assessing the risk of pancreatic cancer and insulin use [151]. The variations seen in these studies can be explained by the complexity of this issue and differing study populations, comorbid conditions, environmental influences, and study durations. Although these and other studies have demonstrated the association between both endogenous insulin and exogenous insulin therapy and the risk of cancer or tumor progression, randomized, longterm studies are needed to evaluate further the safety of insulin analogs and establish with certainty the effect of diabetes therapies on cancer progression. Therefore, molecular characteristics of insulin analogs during safety evaluation play an important role in identifying the mitogenic activities of these analogs [152]. The molecular characteristics of the basal insulin analogs glargine and detemir compared with human insulin, IGF-1, and the super-mitogenic insulin X10 were assessed by measuring the binding of ligands to membrane-bound and solubilized receptors, receptor activation, and mitogenicity in a number of cell types [152]. The study demonstrated that the molecular characteristics of glargine and detemir do not differ from human insulin, and neither analog has an increased mitogenic effect in 
cells that predominantly express insulin receptor. X10 and glargine displayed an increased relative binding affinity for the IGF-1 and, consequently, exhibit increased mitogenic activities. X10 is more mitogenic than human insulin in both insulin receptor and IGF-1 receptor-expressing cells. The authors concluded that none of the molecular data presented in this study suggest any safety concern with detemir [152].

\section{CONCLUSION}

Animal insulin products were the first type of insulin available for treating patients with diabetes; however, their impurities were associated with side effects. In order to address those concerns, the development of synthetic and recombinant "human" insulins provided greater purity and substantially decreased the risks of insulin allergy and lipoatrophy. Eventually, long-acting insulin analogs were developed to provide a longer duration of action, along with less intrapatient variability, pronounced peak in time-action profiles, and risk of hypoglycemia than their human-derived counterparts. There are several current trials demonstrating that an ultra-long-acting insulin analog in development is safer, based on reduced incidence of hypoglycemia, and as effective as currently available basal insulin analogs. Because many patients with diabetes still have difficulty reaching and maintaining glycemic control on currently available insulins, new insulin options are a welcome addition, particularly those such as insulin degludec, which may also provide patients greater flexibility in time of dosing.

Long-acting and rapid-acting insulin analogs better simulate endogenous insulin secretion, and can provide both basal and bolus coverage when used as a premixed formulation. Insulin premixes offer improved glycemic control, decreased intrapatient variability versus self-mixing, and the potential for fewer injections per day. In addition, rapid-acting insulin analogs can be taken right before a meal and long-acting insulin analogs more closely mimic the normal physiologic insulin response due to their flatter time-action profiles.

While there have been many advances in efficacy, safety, and now even patient flexibility and convenience based on pharmacokinetics and mechanisms of delivery since the first insulins became available, more improvements are needed and are likely to emerge. Inhaled or oral insulin currently in development can further add to patient convenience. Additional studies are needed to obtain more clinically relevant information on optimal treatment strategies for patients with diabetes who are treated with insulin. The potential advantages associated with new types of basal insulin analogs and routes of insulin delivery that have shown promising efficacy results with low rates of hypoglycemia and other adverse events in clinical trials indicate the need for further research. Because diabetes mellitus is associated with an increased risk of macrovascular complications, reducing long-term cardiovascular complications in this patient population becomes an important goal of disease management. Premarketing studies demonstrating macrovascular risk reduction without cardiovascular adverse effect may delay availability of many effective antidiabetic drugs. Therefore, to expedite the approval and release of effective antidiabetic drugs, the FDA recommended that long-term cardiovascular safety studies for antidiabetic drugs be conducted in an established time frame following the approval of antidiabetic drugs [153].

\section{ACKNOWLEDGMENTS}

Dr. Tibaldi is the guarantor for this article, and takes responsibility for the integrity of the work as a whole. The author wishes to thank 
Emma Hitt, PhD, of MedVal Scientific Information Services, LLC for providing medical writing and editorial assistance. This manuscript was prepared according to the International Society for Medical Publication Professionals "Good Publication Practice for Communicating Company-Sponsored Medical Research: the GPP2 Guidelines." Funding to support the preparation of this manuscript was provided by Novo Nordisk Inc.

Conflict of Interest. Dr. Tibaldi is a consultant and a member of a speakers' bureau for Novo Nordisk, is a member of a speakers' bureau for Merck and Daiichi, has received payment for lectures from The Sanofi-Aventis Group and Eli Lilly and Company, has participated in nonpromotional continuing medical education activities sponsored by Eli Lily, SanofiAventis, and Novo Nordisk, and has received payment for the development of educational programs for Novo Nordisk, Eli Lilly, and Sanofi-Aventis. He has participated in two Pri-Med programs, one for Novo Nordisk and one for Eli Lilly, and has developed and presented continuing education programs for AADE sponsored by Sanofi-Aventis. Dr. Tibaldi has indicated that he has no other conflicts of interest with regard to the content of the article.

Open Access. This article is distributed under the terms of the Creative Commons Attribution Noncommercial License, which permits any noncommercial use, distribution, and reproduction in any medium, provided the original author(s) and source are credited.

\section{REFERENCES}

1. Deckert T, Andersen OO, Poulsen JE. The clinical significance of highly purified pig-insulin preparations. Diabetologia. 1974;10:703-8.

2. Hirsch IB. Insulin analogues. $\mathrm{N}$ Engl J Med. 2005;352:174-83.

3. Pieber TR, Treichel HC, Hompesch B, et al. Comparison of insulin detemir and insulin glargine in subjects with type 1 diabetes using intensive insulin therapy. Diabet Med. 2007;24:635-42.
4. Garg SK, Gottlieb PA, Hisatomi ME, et al. Improved glycemic control without an increase in severe hypoglycemic episodes in intensively treated patients with type 1 diabetes receiving morning, evening, or split dose insulin glargine. Diabetes Res Clin Pract. 2004;66:49-56.

5. Devries JH, Nattrass M, Pieber TR. Refining basal insulin therapy: what have we learned in the age of analogues? Diabetes Metab Res Rev. 2007;23:441-54.

6. Mudaliar SR, Lindberg FA, Joyce M, et al. Insulin aspart (B28 asp-insulin): a fast-acting analog of human insulin: absorption kinetics and action profile compared with regular human insulin in healthy nondiabetic subjects. Diabetes Care. 1999;22:1501-6.

7. Cernea S, Raz I. Noninjectable methods of insulin administration. Drugs Today (Barc). 2006;42:405-24.

8. Kalra S, Kalra B, Agrawal N. Oral insulin. Diabetol Metab Syndr. 2010;2:66-9.

9. Still JG. Development of oral insulin: progress and current status. Diabetes Metab Res Rev. 2002;18 (Suppl. 1):S29-S37.

10. Howey DC, Bowsher RR, Brunelle RL, Woodworth JR. [Lys(B28), Pro(B29)]-human insulin. A rapidly absorbed analogue of human insulin. Diabetes. 1994;43:396-402.

11. Davis SN. Insulin, oral hypoglycemic agents, and the pharmacology of the endocrine pancreas. In: Brunton LL, Lazo JS, Parker KL, eds. Goodman \& Gilman's The Pharmacological Basis of Therapeutics. 11th edition. New York: McGrawHill; 2006:1613-45.

12. Felig P. Landmark perspective: protamine insulin. Hagedorn's pioneering contribution to drug delivery in the management of diabetes. JAMA. 1984;251:393-6.

13. Rosenfeld L. Insulin: discovery and controversy. Clin Chem. 2002;48:2270-88.

14. Marble A. Hypoglycemia due to insulin. N Engl J Med. 1937;217:130-6.

15. Krayenbuhl C, Rosenberg T. Crystalline protamine insulin. Rep Steno Mem Hosp. 1946;1:60-73.

16. Vajo Z, Fawcett J, Duckworth WC. Recombinant DNA technology in the treatment of diabetes: insulin analogs. Endocr Rev. 2001;22:706-17. 
17. Heinemann L, Linkeschova R, Rave K, Hompesch B, Sedlak M, Heise T. Time-action profile of the long-acting insulin analog insulin glargine (HOE901) in comparison with those of NPH insulin and placebo. Diabetes Care. 2000;23:644-9.

18. Binder C, Lauritzen T, Faber O, Pramming S. Insulin pharmacokinetics. Diabetes Care. 1984;7:188-99.

19. Guthrie R. Is there a need for better basal insulin? Clin Diabetes. 2001;19:66-70.

20. Wright AD, Walsh $\mathrm{CH}$, Fitzgerald MG, Malins JM. Very pure porcine insulin in clinical practice. BMJ. 1979;1:25-7.

21. McNally PG, Jowett NI, Kurinczuk JJ, Peck RW, Hearnshaw JR. Lipohypertrophy and lipoatrophy complicating treatment with highly purified bovine and porcine insulins. Postgrad Med J. 1988;64:850-3.

22. Koenig RJ, Peterson CM, Jones RL, Saudek C, Lehrman M, Cerami A. Correlation of glucose regulation and hemoglobin AIc in diabetes mellitus. N Engl J Med. 1976;295:417-20.

23. Lebovitz HE, Austin MM, Blonde L, et al. ACE/ AACE consensus conference on the implementation of outpatient management of diabetes mellitus: consensus conference recommendations. Endocr Pract. 2006;12 (Suppl. 1):6-12.

24. Tominaga M, Eguchi H, Manaka H, Igarashi K, Kato T, Sekikawa A. Impaired glucose tolerance is a risk factor for cardiovascular disease, but not impaired fasting glucose. The Funagata Diabetes Study. Diabetes Care. 1999;22:920-4.

25. Holman RR, Haffner SM, McMurray JJ, et al. Effect of nateglinide on the incidence of diabetes and cardiovascular events. $\mathrm{N}$ Engl J Med. 2010;362:1463-76.

26. Raz I, Ceriello A, Wilson PW, et al. Post hoc subgroup analysis of the HEART2D trial demonstrates lower cardiovascular risk in older patients targeting postprandial versus fasting/premeal glycemia. Diabetes Care. 2011;34:1511-13.

27. Kung YT, Du YC, Huang WT, Chen CC, Ke LT. Total synthesis of crystalline insulin. Sci Sin. 1966;15:544-61.

28. Katsoyannis PG, Tometsko A, Zalut C. Insulin peptides. XII. Human insulin generation by combination of synthetic A and B chains. J Am Chem Soc. 1966;88:166-7.
29. Teuscher A. The biological effect of purely synthetic human insulin in patients with diabetes mellitus. Schweiz Med Wochenschr. 1979;109:743-7. In German.

30. Zhang Y. The first protein ever synthesized in vitro - a personal reminiscence of the total synthesis of crystalline insulin. Sci China Life Sci. 2010;53:16-18.

31. Owens DR, Jones MK, Hayes TM, et al. Human insulin: study of safety and efficacy in man. BMJ (Clin Res Ed). 1981;282:1264-6.

32. Sestoft L, Volund A, Gammeltoft S, Birch K, Hildebrandt P. The biological properties of human insulin. Subcutaneous absorption, receptor binding and the clinical effect in diabetics assessed by a new statistical method. Acta Med Scand. 1982;212:21-8.

33. Goeddel DV, Kleid DG, Bolivar F, et al. Expression in Escherichia coli of chemically synthesized genes for human insulin. Proc Natl Acad Sci U S A. 1979;76:106-10.

34. Joshi SR, Parikh RM, Das AK. Insulin - history, biochemistry, physiology and pharmacology. J Assoc Physicians India. 2007;55 (Suppl.):19-25.

35. Powers AC. Diabetes Mellitus. In: Longo DL, Fauci AS, Kasper DL, et al., eds. Harrison's Principles of Internal Medicine. 18th edition. New York: McGraw-Hill; 2012: 2968-3002.

36. Eli Lilly and Company. Heritage. Available at: http://www.lilly.com/about/heritage/Pages/ heritage.aspx. Accessed July 17, 2012.

37. Eli Lilly and Company. Humulin ${ }^{\circledR}$ R (regular insulin human injection [rDNA origin]) 100 units per $\mathrm{mL}$ (U-100) [prescribing information]. Indianapolis, IN: Eli Lilly and Company; March 25, 2011.

38. Eli Lilly and Company. Humulin ${ }^{\circledR}$ N (NPH human insulin [rDNA origin]) [prescribing information]. Indianapolis, IN: Eli Lilly and Company; September 2, 2009.

39. Keen H, Glynne A, Pickup JC, et al. Human insulin produced by recombinant DNA technology: safety and hypoglycaemic potency in healthy men. Lancet. 1980;2:398-401.

40. Novo Nordisk Inc. Milestones in Novo Nordisk's history. Available at: http://www.novonordisk. com/about_us/history/milestones_in_nn_history. asp. Accessed July 17, 2012. 
41. Brunton S. Safety and effectiveness of modern insulin therapy: the value of insulin analogs. Consultant. 2009;July 29 (Suppl.):S13-S19.

42. Clark AJ, Adeniyi-Jones RO, Knight G, et al. Biosynthetic human insulin in the treatment of diabetes. A double-blind crossover trial in established diabetic patients. Lancet. 1982;2:354-7.

43. Hildebrandt P, Birch K, Sestoft L, Volund A. Dosedependent subcutaneous absorption of porcine, bovine and human NPH insulins. Acta Med Scand. 1984;215:69-73.

44. Heinemann L. Do insulin-treated diabetic patients use an injection-meal-interval in daily life? Diabet Med. 1995;12:449-50.

45. Eli Lilly and Company. Humulin ${ }^{\circledR} \quad 70 / 30 \quad 70 \%$ human insulin isophane suspension and 30\% human insulin injection (rDNA origin) 100 units per ML (U-100) [prescribing information]. Indianapolis, IN: Eli Lilly and Company; January 20, 2011.

46. Novo Nordisk Inc. Novolin ${ }^{\circledR}$ 70/30 [patient information]. Princeton, NJ: Novo Nordisk Inc.; May 14, 2010.

47. Molife C, Lee LJ, Shi L, Sawhney M, Lenox SM. Assessment of patient-reported outcomes of insulin pen devices versus conventional vial and syringe. Diabetes Technol Ther. 2009;11:529-38.

48. Hartman I. Insulin analogs: impact on treatment success, satisfaction, quality of life, and adherence. Clin Med Res. 2008;6:54-67.

49. Yamada S. Insulin glulisine in the management of diabetes. Diabetes Metab Syndr Obes. 2009;2:111-15.

50. Owens DR. Insulin preparations with prolonged effect. Diabetes Technol Ther. 2011;13 (Suppl. 1):S5-S14.

51. Poon K, King AB. Glargine and detemir: safety and efficacy profiles of the long-acting basal insulin analogs. Drug Healthc Patient Saf. 2010;2:213-23.

52. Novo Nordisk Inc. Levemir ${ }^{\circledR}$ (insulin detemir [rDNA origin] injection) [prescribing information]. Princeton, NJ: Novo Nordisk Inc.; May 18, 2012.

53. Sanofi-Aventis U.S. Lantus ${ }^{\circledR}$ (insulin glargine [rDNA origin] injection) [prescribing information]. Bridgewater, NJ: Sanofi-Aventis; April, 2010.

54. Owens DR, Coates PA, Luzio SD, Tinbergen JP, Kurzhals R. Pharmacokinetics of 125I-labeled insulin glargine (HOE 901) in healthy men: comparison with NPH insulin and the influence of different subcutaneous injection sites. Diabetes Care. 2000;23:813-19.
55. Porcellati F, Rossetti P, Ricci BN, et al. Comparison of pharmacokinetics and dynamics of the longacting insulin analogs glargine and detemir at steady state in type 1 diabetes mellitus: a doubleblind, randomized, cross-over study. Diabetes Care. 2007;30:2447-51.

56. Plank J, Bodenlenz M, Sinner F, et al. A double-blind, randomized, dose-response study investigating the pharmacodynamic and pharmacokinetic properties of the long-acting insulin analog detemir. Diabetes Care. 2005;28:1107-12.

57. Klein O, Lynge J, Endahl L, Damholt B, Nosek L, Heise T. Albumin-bound basal insulin analogues (insulin detemir and NN344): comparable timeaction profiles but less variability than insulin glargine in type 2 diabetes. Diabetes Obes Metab. 2007;9:290-9.

58. Bolli GB, Luzio S, Marzotti S, et al. Comparative pharmacodynamic and pharmacokinetic characteristics of subcutaneous insulin glulisine and insulin aspart prior to a standard meal in obese subjects with type 2 diabetes. Diabetes Obes Metab. 2011;13:251-7.

59. Rave K, Bott S, Heinemann L, et al. Time-action profile of inhaled insulin in comparison with subcutaneously injected insulin lispro and regular human insulin. Diabetes Care. 2005;28:1077-82.

60. Tamas G, Marre M, Astorga R, Dedov I, Jacobsen J, Lindholm A. Glycaemic control in type 1 diabetic patients using optimised insulin aspart or human insulin in a randomised multinational study. Diabetes Res Clin Pract. 2001;54:105-14.

61. Homko C, Deluzio A, Jimenez C, Kolaczynski JW, Boden G. Comparison of insulin aspart and lispro: pharmacokinetic and metabolic effects. Diabetes Care. 2003;26:2027-31.

62. Becker RH, Frick AD. Clinical pharmacokinetics and pharmacodynamics of insulin glulisine. Clin Pharmacokinet. 2008;47:7-20.

63. Becker RHA, Frick AD, Burger F, Potgieter JH, Scholtz H. Insulin glulisine, a new rapid-acting insulin analogue, displays a rapid time-action profile in obese non-diabetic subjects. Exp Clin Endocrinol Diabetes. 2005;113:435-43.

64. Heise T, Nosek L, Spitzer H, et al. Insulin glulisine: a faster onset of action compared with insulin lispro. Diabetes Obes Metab. 2007;9:746-53. 
65. Luzio S, Peter R, Dunseath GJ, Mustafa L, Owens DR. A comparison of preprandial insulin glulisine versus insulin lispro in people with type 2 diabetes over a 12-h period. Diabetes Res Clin Pract. 2008;79:269-75.

66. Meyer C, Boron A, Plummer E, Voltchenok M, Vedda R. Glulisine versus human regular insulin in combination with glargine in noncritically ill hospitalized patients with type 2 diabetes: a randomized double-blind study. Diabetes Care. 2010;33:2496-501.

67. Home PD, Barriocanal L, Lindholm A. Comparative pharmacokinetics and pharmacodynamics of the novel rapid-acting insulin analogue, insulin aspart, in healthy volunteers. Eur J Clin Pharmacol. 1999;55:199-203.

68. Rolla A. Pharmacokinetic and pharmacodynamic advantages of insulin analogues and premixed insulin analogues over human insulins: impact on efficacy and safety. Am J Med. 2008;121 (6 Suppl.):S9-S19.

69. Garber AJ, Ligthelm R, Christiansen JS, Liebl A. Premixed insulin treatment for type 2 diabetes: analogue or human? Diabetes Obes Metab. 2007;9:630-9.

70. Hermansen $\mathrm{K}$, Colombo $\mathrm{M}$, Storgaard $\mathrm{H}$, OStergaard A, Kolendorf K, Madsbad S. Improved postprandial glycemic control with biphasic insulin aspart relative to biphasic insulin lispro and biphasic human insulin in patients with type 2 diabetes. Diabetes Care. 2002;25:883-8.

71. Weyer C, Heise T, Heinemann L. Insulin aspart in a 30/70 premixed formulation. Pharmacodynamic properties of a rapid-acting insulin analog in stable mixture. Diabetes Care. 1997;20:1612-14.

72. Heise T, Heinemann L, Hovelmann $U$, et al. Biphasic insulin aspart 30/70 (BIAsp 30): pharmacokinetics (PK) and pharmacodynamics (PD) in comparison with once-daily biphasic human insulin and basal-bolus therapy. Diabetes Care. 2009;32:1431-3.

73. Handelsman Y, Mechanick JI, Blonde L, et al. American Association of Clinical Endocrinologists Medical Guidelines for Clinical Practice for developing a diabetes mellitus comprehensive care plan. Endocr Pract. 2011;17 (Suppl. 2):1-53.

74. American Diabetes Association. Defining and reporting hypoglycemia in diabetes: a report from the American Diabetes Association Workgroup on Hypoglycemia. Diabetes Care. 2005;28:1245-9.
75. Taborsky GJ, Ahren B, Havel PJ. Autonomic mediation of glucagon secretion during hypoglycemia: implications for impaired a-cell responses in type 1 diabetes. Diabetes. 1998;47:995-1005.

76. Bolli G, De Feo P, Compagnucci P, et al. Abnormal glucose counterregulation in insulin-dependent diabetes mellitus. Interaction of anti-insulin antibodies and impaired glucagon and epinephrine secretion. Diabetes. 1983;32:134-41.

77. Cryer PE. Banting Lecture. Hypoglycemia: the limiting factor in the management of IDDM. Diabetes. 1994;43:1378-89.

78. Cryer PE. Hypoglycemia in Diabetes: Pathophysiology, Prevalence, and Prevention. Alexandria, VA: American Diabetes Association; 2009.

79. UK Hypoglycaemia Study Group. Risk of hypoglycaemia in types 1 and 2 diabetes: effects of treatment modalities and their duration. Diabetologia. 2007;50:1140-7.

80. United Kingdom Prospective Diabetes Study 24. A 6-year, randomized, controlled trial comparing sulfonylurea, insulin, and metformin therapy in patients with newly diagnosed type 2 diabetes that could not be controlled with diet therapy. United Kingdom Prospective Diabetes Study Group. Ann Intern Med. 1998;128:165-75.

81. Rys P, Pankiewicz O, Lach K, Kwaskowski A, Skrzekowska-Baran I, Malecki MT. Efficacy and safety comparison of rapid-acting insulin aspart and regular human insulin in the treatment of type 1 and type 2 diabetes mellitus: a systematic review. Diabetes Metab. 2011;37:190-200.

82. Brunetti P, Muggeo M, Cattin L, et al. Incidence of severe nocturnal hypoglycemia in patients with type 1 diabetes treated with insulin lispro or regular human insulin in addition to basal insulin glargine. Nutr Metab Cardiovasc Dis. 2010;20:519-26.

83. Riddle MC, Rosenstock J, Gerich J. The Treat-toTarget trial: randomized addition of glargine or human NPH insulin to oral therapy of type 2 diabetic patients. Diabetes Care. 2003;26:3080-6.

84. The ORIGIN Trial Investigators. Basal insulin and cardiovascular and other outcomes in dysglycemia. N Engl J Med. 2012; Jun 11 [Epub ahead of print].

85. Le Floch JP. Critical appraisal of the safety and efficacy of insulin detemir in glycemic control and cardiovascular risk management in diabetics. Diabetes Metab Syndr Obes. 2010;3:197-213. 
86. Hermansen K, Davies M, Derezinski T, Ravn GM, Clauson P, Home P. A 26-week, randomized, parallel, treat-to-target trial comparing insulin detemir with NPH insulin as add-on therapy to oral glucose-lowering drugs in insulin-naive people with type 2 diabetes. Diabetes Care. 2006;29:1269-74.

87. Philis-Tsimikas A, Charpentier G, Clauson P, Martinez Ravn G, Roberts VL, Thorsteinsson B. Comparison of once-daily insulin detemir with $\mathrm{NPH}$ insulin added to a regimen of oral antidiabetic drugs in poorly controlled type 2 diabetes. Clin Ther. 2006;28:1569-81.

88. Martorella AJ. Iatrogenic hypoglycemia in patients with type 2 diabetes: comparison of insulin analog premixes and human insulin premixes. Postgrad Med. 2011;123:7-16.

89. Davidson JA, Liebl A, Christiansen JS, et al. Risk for nocturnal hypoglycemia with biphasic insulin aspart 30 compared with biphasic human insulin 30 in adults with type 2 diabetes mellitus: a metaanalysis. Clin Ther. 2009;31:1641-51.

90. Morgan CL, Evans M, Toft AD, Jenkins-Jones S, Poole CD, Currie CJ. Clinical effectiveness of biphasic insulin aspart 30:70 versus biphasic human insulin 30 in UK general clinical practice: a retrospective database study. Clin Ther. 2011;33:27-35.

91. Valensi $\mathrm{P}$, Benroubi $\mathrm{M}$, Borzi $\mathrm{V}$, et al. Initiating insulin therapy with, or switching existing insulin therapy to, biphasic insulin aspart 30/70 (NovoMix 30) in routine care: safety and effectiveness in patients with type 2 diabetes in the IMPROVETM observational study. Int J Clin Pract. 2009;63:522-31.

92. Anderson JH Jr., Brunelle RL, Koivisto VA, et al. Reduction of postprandial hyperglycemia and frequency of hypoglycemia in IDDM patients on insulin-analog treatment. Multicenter Insulin Lispro Study Group. Diabetes. 1997;46:265-70.

93. Home PD, Lindholm A, Hylleberg B, Round P. Improved glycemic control with insulin aspart: a multicenter randomized double-blind crossover trial in type 1 diabetic patients. Diabetes Care. 1998;21:1904-9.

94. Garg S, Ampudia-Blasco FJ, Pfohl M. Rapid-acting insulin analogues in basal-bolus regimens in type 1 diabetes mellitus. Endocr Pract. 2010;16:486-505.

95. American Diabetes Association. Standards of medical care in diabetes - 2012. Diabetes Care. 2012;35 (Suppl. 1):S11-S63.
96. Lepore M, Pampanelli S, Fanelli C, et al. Pharmacokinetics and pharmacodynamics of subcutaneous injection of long-acting human insulin analog glargine, NPH insulin, and ultralente human insulin and continuous subcutaneous infusion of insulin lispro. Diabetes. 2000;49:2142-8.

97. Hermansen K, Fontaine P, Kukolja KK, Peterkova V, Leth G, Gall MA. Insulin analogues (insulin detemir and insulin aspart) versus traditional human insulins (NPH insulin and regular human insulin) in basal-bolus therapy for patients with type 1 diabetes. Diabetologia. 2004;47:622-9.

98. Davidson MB, Navar MD, Echeverry D, Duran P. U-500 regular insulin: clinical experience and pharmacokinetics in obese, severely insulin-resistant type 2 diabetic patients. Diabetes Care. 2010;33:281-3.

99. Garg R, Johnston V, McNally PG, Davies MJ, Lawrence IG. U-500 insulin: why, when and how to use in clinical practice. Diabetes Metab Res Rev. 2007;23:265-8.

100. Lane WS, Cochran EK, Jackson JA, et al. Highdose insulin therapy: is it time for U-500 insulin? Endocr Pract. 2009;15:71-9.

101. De La Pena A, Riddle M, Morrow LA, et al. Pharmacokinetics and pharmacodynamics of highdose human regular U-500 insulin versus human regular U-100 insulin in healthy obese subjects. Diabetes Care. 2011;34:2496-501.

102. Lowery JB, Donihi AC, Korytkowski MT. U-500 insulin as a component of basal bolus insulin therapy in type 2 diabetes. Diabetes Technol Ther. 2012;14:505-7.

103. Heise T, Tack CJ, Cuddihy R, et al. A newgeneration ultra-long-acting basal insulin with a bolus boost compared with insulin glargine in insulin-naive people with type 2 diabetes: a randomized, controlled trial. Diabetes Care. 2011;34:669-74.

104. Birkeland KI, Home PD, Wendisch U, et al. Insulin degludec in type 1 diabetes: a randomized controlled trial of a new-generation ultra-longacting insulin compared with insulin glargine. Diabetes Care. 2011;34:661-5.

105. Simon AC, Devries JH. The future of basal insulin supplementation. Diabetes Technol Ther. 2011;31(Suppl. 1):S108.

106. Jonassen I, Havelund S, Hoeg-Jensen T, Steensgaard DB, Wahlund PO, Ribel U. Design of the novel protraction mechanism of insulin degludec, an ultra-long-acting basal insulin. Pharmaceutical Research. 2012; Apr 7 [Epub ahead of print]. 
107. Arnolds S, Kuglin B, Kapitza C, Heise T. How pharmacokinetic and pharmacodynamic principles pave the way for optimal basal insulin therapy in type 2 diabetes. Int J Clin Pract. 2010;64:1415-34. Available at: http://professional. diabetes. org/ Abstracts_Display. $\quad$ aspx?TYP $=1 \& C I D=86498$. Accessed July 10, 2012.

108. Heise T, Hovelmann U, Nosek L, Bottcher SG, Granhall C, Haahr H. Insulin degludec: two-fold longer half-life and more consistent pharmacokinetic profile than insulin glargine. Diabetologia. 2011;54:s425.

109. Heller S, Francisco AM, Pei H, Russell-Jones D. Insulin degludec improves long-term glycemic control with less nocturnal hypoglycemia compared with insulin glargine: 1-year results from a randomized basal-bolus trial in type 1 diabetes [abstract]. Diabetes. 2011;60:A19.

110. Garber AJ, King AB, Del PS, et al. Insulin degludec, an ultra-long-acting basal insulin, versus insulin glargine in basal-bolus treatment with mealtime insulin aspart in type 2 diabetes (BEGIN BasalBolus Type 2): a phase 3, randomised, openlabel, treat-to-target non-inferiority trial. Lancet. 2012;379:1498-507.

111. Meneghini L, Atkin S, Bain S, et al. Flexible once-daily dosing of insulin degludec does not compromise glycemic control or safety compared to insulin glargine given once daily at the same time each day in people with type 2 diabetes [abstract]. Diabetes. 2011;60 (Suppl. 1A):LB10-LB11.

112. Vaag A, Leiter LL, Franek E, et al. Use of new basal insulin with a bolus boost (IDegAsp) in type 2 diabetes: comparison with biphasic insulin aspart 30 (BIAsp 20) [abstract]. Am Diabetes Assoc. 2012; Diabetes. 2011;60 (Suppl. 1A):1141-P.

113. Hirsch IB, Franek E, Courreges J-P, Mersebach H, Dykiel P, Bode BW. Efficacy and safety of a new basal insulin with a bolus boost (IDegAsp) used once daily in combination with insulin aspart (IAsp) in people with type 1 diabetes [abstract]. Diabetes. 2011;60:A292.

114. Heise T, Nosek L, Hovelmann U, Bottcher SG, Hastrup H, Haahr H. Insulin degludec $200 \mathrm{U} / \mathrm{ml}$ is ultra-long-acting and has a flat and stable glucoselowering effect. Philadelphia, PA: American Diabetes Association; June 8-12, 2012.

115. Korsatko S, Deller S, Zahiragic S, et al. Ultralong-acting insulin degludec: bioequivalence and similar pharmacodynamics shown for two different formulations $(100 \mathrm{U} / \mathrm{ml}$ and $200 \mathrm{U} / \mathrm{ml})$. Lisbon, Portugal: European Association for the Study of Diabetes; September 12-16, 2011.
116. Bastyr EJ, Bergenstal RM, Rosenstock J, Prince MJ, Qu Y, Jacober SJ. The novel long-acting insulin LY2605541 is superior to insulin glargine in lowering intra-day glucose variability and hypoglycemia event rate from continuous glucose monitoring (CGM) in patients with type 2 diabetes. Philadelphia, PA: American Diabetes Association; June 8-12, 2012.

117. Bergenstal RM, Rosenstock J, Arakaki RF, et al. Reduced nocturnal hypoglycemia and weight loss with novel long-acting basal insulin LY2605541 compared with insulin glargine in patients with type 2 diabetes. Philadelphia, PA: American Diabetes Association; June 8-12, 2012.

118. Hollander PA, Blonde L, Rowe R, et al. Efficacy and safety of inhaled insulin (exubera) compared with subcutaneous insulin therapy in patients with type 2 diabetes: results of a 6-month, randomized, comparative trial. Diabetes Care. 2004;27:2356-62.

119. Quattrin T, Belanger A, Bohannon NJ, et al. Efficacy and safety of inhaled insulin (exubera) compared with subcutaneous insulin therapy in patients with type 1 diabetes: results of a 6-month, randomized, comparative trial. Diabetes Care. 2004;27:2622-7.

120. Mastrandrea LD. Inhaled insulin: overview of a novel route of insulin administration. Vasc Health Risk Manag. 2010;6:47-58.

121. Moses RG, Bartley P, Lunt H, et al. Safety and efficacy of inhaled insulin (AERx iDMS) compared with subcutaneous insulin therapy in patients with type 1 diabetes: 1-year data from a randomized, parallel group trial. Diabet Med. 2009;26:260-7.

122. Rave K, Heise T, Pfutzner A, Boss AH. Coverage of postprandial blood glucose excursions with inhaled technosphere insulin in comparison to subcutaneously injected regular human insulin in subjects with type 2 diabetes. Diabetes Care. 2007;30:2307-8.

123. Khedkar A, Iyer $\mathrm{H}$, Anand $\mathrm{A}$, et al. A dose range finding study of novel oral insulin (IN-105) under fed conditions in type 2 diabetes mellitus subjects. Diabetes Obes Metab. 2010;12:659-64.

124. Kapitza C, Zijlstra E, Heinemann L, Castelli MC, Riley G, Heise T. Oral insulin: a comparison with subcutaneous regular human insulin in patients with type 2 diabetes. Diabetes Care. 2010;33:1288-90.

125. Coughlin SS, Calle EE, Teras LR, Petrelli J, Thun MJ. Diabetes mellitus as a predictor of cancer mortality in a large cohort of US adults. Am J Epidemiol. 2004;159:1160-7. 
126. Pollak M. Targeting insulin and insulin-like growth factor signalling in oncology. Curr Opin Pharmacol. 2008;8:384-92.

127. Friberg E, Orsini N, Mantzoros CS, Wolk A. Diabetes mellitus and risk of endometrial cancer: a meta-analysis. Diabetologia. 2007;50:1365-74.

128. Huxley R, Ansary-Moghaddam A, Berrington de Gonzalez A, Barzi F, Woodward M. Type-II diabetes and pancreatic cancer: a meta-analysis of 36 studies. Br J Cancer. 2005;92:2076-83.

129. Larsson SC, Orsini N, Wolk A. Diabetes mellitus and risk of colorectal cancer: a meta-analysis. J Natl Cancer Inst. 2005;97:1679-87.

130. Larsson SC, Orsini N, Brismar K, Wolk A. Diabetes mellitus and risk of bladder cancer: a metaanalysis. Diabetologia. 2006;49:2819-23.

131. Larsson SC, Mantzoros CS, Wolk A. Diabetes mellitus and risk of breast cancer: a meta-analysis. Int J Cancer. 2007;121:856-62.

132. Currie CJ, Poole CD, Gale EA. The influence of glucose-lowering therapies on cancer risk in type 2 diabetes. Diabetologia. 2009;52:1766-7.

133. Gunter MJ, Hoover DR, Yu $\mathrm{H}$, et al. Insulin, insulin-like growth factor-I, and risk of breast cancer in postmenopausal women. J Natl Cancer Inst. 2009;101:48-60.

134. Redinger RN. The pathophysiology of obesity and its clinical manifestations. Gastroenterol Hepatol. 2007;3:856-63.

135. Yang YX, Hennessy S, Lewis JD. Insulin therapy and colorectal cancer risk among type 2 diabetes mellitus patients. Gastroenterology. 2004;127:1044-50.

136. Chitnis MM, Yuen JS, Protheroe AS, Pollak M, Macaulay VM. The type 1 insulin-like growth factor receptor pathway. Clin Cancer Res. 2008;14:6364-70.

137. Leitner JW, Kline T, Carel K, Goalstone M, Draznin B. Hyperinsulinemia potentiates activation of p21Ras by growth factors. Endocrinology. 1997;138:2211-14.

138. Finlayson CA, Chappell J, Leitner JW, et al. Enhanced insulin signaling via Shc in human breast cancer. Metabolism. 2003;52:1606-11.

139. Wang CC, Goalstone ML, Draznin B. Molecular mechanisms of insulin resistance that impact cardiovascular biology. Diabetes. 2004;53:2735-40.
140. Zib I, Raskin P. Novel insulin analogues and its mitogenic potential. Diabetes Obes Metab. 2006;8:611-20.

141. Zelobowska K, Gumprecht J, Grzeszczak W. Mitogenic potency of insulin glargine. Endokrynol Pol. 2009;60:34-9.

142. Draznin B. Mitogenic action of insulin: friend, foe or 'frenemy'? Diabetologia. 2010;53:229-33.

143. Hemkens LG, Grouven U, Bender R, et al. Risk of malignancies in patients with diabetes treated with human insulin or insulin analogues: a cohort study. Diabetologia. 2009;52:1732-44.

144. Chung YW, Han DS, Park KH, Eun CS, Yoo KS, Park CK. Insulin therapy and colorectal adenoma risk among patients with type 2 diabetes mellitus: a case-control study in Korea. Dis Colon Rectum. 2008;51:593-7.

145. Siddiqui AA, Spechler SJ, Huerta S, Dredar S, Little $\mathrm{BB}$, Cryer B. Elevated $\mathrm{HbA} 1 \mathrm{c}$ is an independent predictor of aggressive clinical behavior in patients with colorectal cancer: a case-control study. Dig Dis Sci. 2008;53:2486-94.

146. Saydah SH, Platz EA, Rifai N, Pollak MN, Brancati FL, Helzlsouer KJ. Association of markers of insulin and glucose control with subsequent colorectal cancer risk. Cancer Epidemiol Biomarkers Prev. 2003;12:412-18.

147. Bonelli L, Aste H, Bovo P, et al. Exocrine pancreatic cancer, cigarette smoking, and diabetes mellitus: a case-control study in northern Italy. Pancreas. 2003;27:143-9.

148. Komura T, Mizukoshi E, Kita Y, et al. Impact of diabetes on recurrence of hepatocellular carcinoma after surgical treatment in patients with viral hepatitis. Am J Gastroenterol. 2007;102:1939-46.

149. Silverman DT, Schiffman M, Everhart J, et al. Diabetes mellitus, other medical conditions and familial history of cancer as risk factors for pancreatic cancer. Br J Cancer. 1999;80:1830-7.

150. Pierce BL, Plymate S, Ostrander EA, Stanford JL. Diabetes mellitus and prostate cancer risk. Prostate. 2008;68:1126-32.

151. Velicer CM, Dublin S, White E. Diabetes and the risk of prostate cancer: the role of diabetes treatment and complications. Prostate Cancer Prostatic Dis. 2007;10:46-51. 
152. Hansen BF, Glendorf T, Hegelund AC, et al. Molecular characterisation of long-acting insulin analogues in comparison with human insulin, IGF-1 and insulin X10. PLoS One. 2012; 7:e34274.
153. U.S. Food and Drug Administration. Guidance for industry diabetes mellitus: developing drugs and therapeutic biologics for treatment and prevention (draft). Rockville, MD: U.S. Food and Drug Administration; February, 2008. 